\title{
On-Site Inspection Radiolsotopic Spectroscopy (OsIRIS) System-Integration and Field-Testing Report
}

\author{
A.J. Caffrey, W.A. Alston, K.M. Krebs, M.L. Wetzel, and C.J. Wharton \\ Idaho National Laboratory \\ N.G. Wimer \\ Lawrence Livermore National Laboratory \\ G.A. Warren, D.V. Jordan, B.D. Milbrath, and M.A. Zalavadia \\ Pacific Northwest National Laboratory
}

October 2018

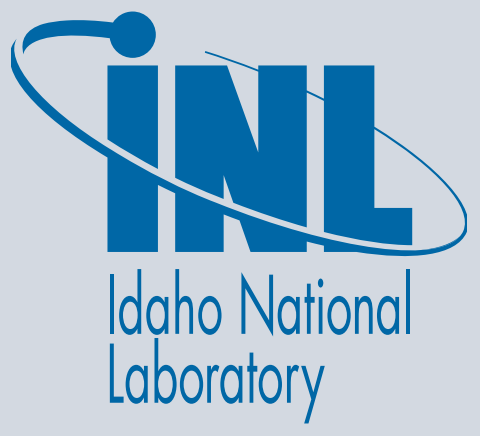

INL is a U.S. Department of Energy National Laboratory operated by Battelle Energy Alliance 


\section{Disclaimer}

This report was prepared as an account of work sponsored by an agency of the United States Government. Neither the United States Government nor any agency thereof, nor any of their employees, makes any warranty, express or implied, or assumes any legal liability or responsibility for the accuracy, completeness, or usefulness of any information, apparatus, product or process disclosed, or represents that its use would not infringe privately owned rights. References herein to any specific commercial product, process, or service by trade name, trademark, manufacturer, or otherwise, does not necessarily constitute or imply its endorsement, recommendation, or favoring by the United States Government or any agency thereof. The views and opinions of authors expressed herein do not necessarily state or reflect those of the United States Government or any agency thereof. 


\section{Abstract}

e have designed a system for the acquisition and analysis of high-resolution gamma-ray spectra during on-site inspections under the Comprehensive Nuclear-Test-Ban Treaty (CTBT).

The On-Site Inspection Radiolsotopic Spectroscopy_OsIRIS — gamma-ray spectrometer is a mechanically-cooled, battery-powered ORTEC IDM-200V, chosen to avoid the need for liquid nitrogen during on-site inspections. The spectrometer is controlled and the spectral data analyzed by a ruggedized notebook computer. Spectral data analysis is similar to that performed by traditional gamma-ray spectrometers, except the OsIRIS gamma-ray spectral data are filtered to display only radioisotopic information relevant to CTBT on-site inspections, for example, the fission-product isotope zirconium-96 (Zr-95) and its daughter isotope Nb-95.

The OsIRIS software assists the user during operation with software checklists for startup and shutdown, and menu-selected display windows during energy calibration and data acquisition. OSIRIS can be operated in either sample-counting mode or the in-situ mode.

In this report, the extensive system-integration tests of the OsIRIS system carried out in 2015-2017 are described, including tests at Idaho National Laboratory, at the Nevada National Security Site (formerly, the Nevada Test Site), and at Pacific Northwest National Laboratory in Richland, Washington. We also note recent software enhancements and the steps to our successful commercialization of OsIRIS. 


\section{Table of Contents}

1. Introduction $\ldots \ldots \ldots \ldots \ldots \ldots \ldots \ldots \ldots \ldots$

1.1 CTBT On-Site Inspection

Requirements .................... 1

1.2 OSIRIS Design Choices................. 2

1.3 Technology Readiness Level Goal ........ 4

1.4 Performance Metrics..................4

2. OSIRIS Hardware ........................ 5

2.1 Prototype Gamma-Ray Spectrometer. .... . 5

2.2 Gamma-Ray Spectrometer Upgrade...... 6

2.3 Computer $\ldots \ldots \ldots \ldots \ldots \ldots \ldots \ldots \ldots \ldots, 6$

2.4 Auxiliary Equipment ................6

3. OSIRIS Software $\ldots \ldots \ldots \ldots \ldots \ldots \ldots \ldots . \ldots$

3.1 Data Acquisition....................8

3.2 Spectral Analysis....................8

3.2.1 Spectral Analysis Logic .............. 9

3.2.2 Nonlinear Least-Squares

Peak Analysis .................... 10

3.2.3 Spectrometer Energy Calibration . .....10

3.3 Initial Software Tests .................11

3.3.1 Reactor Fuel-Sample Spectra .........11

3.3.2 Synthetic Test Spectra ..............11

3.3.3 Spectral Analysis Test Results ........12

3.4 Radioactivity Determination ...........12

3.4.1 Point-Source Detection Efficiency. . ... 13

3.4.2 Detection Efficiency for In-Situ

Measurements .14
3.4.3 Soil-Sample Detection Efficiency .....15

3.5 Spectral Information for Users...........17

3.5.1 Data Filter.......................17

3.5.2 Bar-Chart Display ................. 18

3.5.3 Isotope Buttons and Information

Windows ...................... 18

3.5.4 Summary Data Output File .......... 18

3.6 Spectral Data Encryption..............21

4. System Integration and Testing ............22

4.1 Energy-Calibration Stability vs.

Temperature ........................22

4.2 Energy-Calibration Stability vs. Time......23

4.3 Cs-134/Cs-137 Ratios ..................23

4.4 Fission-Product Identification amid

Test-Site Legacy Radioactivity..........26

4.5 Fission-Product Identification vs.

Time ..............................27

5. Conclusions $\ldots \ldots \ldots \ldots \ldots \ldots \ldots \ldots \ldots \ldots . .28$

5.1 Design Summary ..................28

5.2 System Test Results ...................28

5.3 Commercialization and Technical

Readiness Level. ...................... 28

Acknowledgments ........................28

References ..............................29 


\section{Introduction}

The On-Site Inspection Radiolsotopic Spectroscopy (OSIRIS) system is a special-purpose spectrometer for on-site inspections under the Comprehensive Nuclear-Test-Ban Treaty (CTBT). [1] The OsIRIS high-resolution spectrometer is controlled by a ruggedized notebook computer running custom data acquisition and data analysis software. The OsIRIS spectrometer and computer are shown in Figure 1.

The spectrometer can be used to identify radioisotopes in samples collected from the soil or, in the "in-situ" counting geometry, it can directly measure radioisotopes deposited on the ground. In either geometry, the spectrometer measures the energy-intensity pattern or spectrum of gamma rays striking the spectrometer germanium crystal. From the energies of the gamma-ray peaks in the spectrum, the emitting radioisotopes are determined, and from the intensities of the peaks, the quantities of each radioisotope can be learned. A fission-product gamma-ray energy spectrum is shown in Figure 2.

In this report, we review the final OsIRIS hardware and software designs and the extensive OSIRIS systems tests conducted from 2015 through 2017.

\subsection{CTBT On-Site Inspection Requirements}

Under the CTBT, each State Party has the right to request an on-site inspection. The treaty and its Protocol allow the use of gamma-ray spectroscopy during on-site inspection, and they also allow for measurement restrictions as a managed access tool by the Inspected State Party. [2]

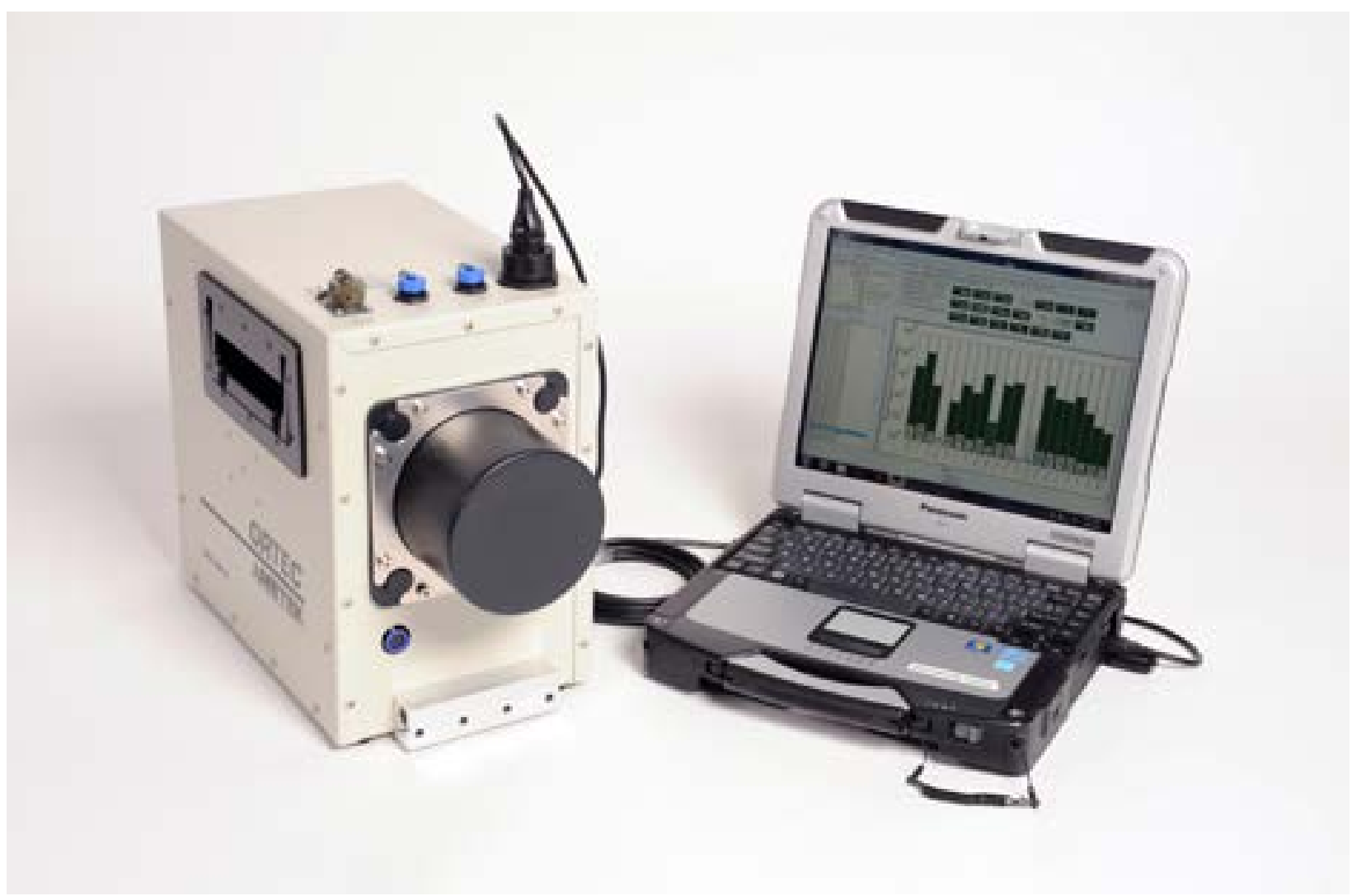

Figure 1. The OSIRIS gamma-ray spectrometer and computer. 
An underground nuclear explosion releases noble gases like the radioxenon isotopes by diffusion through cracks in the rocks, and specialized instruments for on-site noble gas collection and analysis have been developed. [3] If an underground test vents, other radioisotopes may be deposited on the ground as particulate matter, like cesium-137 (Cs-137) and these isotopes are best identified by a gamma-ray spectroscopy system like OsIRIS.

Paragraph 89(b) of the CTBT Protocol limits the radiation measurements to those isotopes and energies relevant to the determination that a nuclear explosion has occurred so as not to disclose irrelevant and potentially proliferation-sensitive information. [4] To minimize the intrusiveness of gamma-ray spectral measurements during on-site inspections, Working Group B of the CTBT Organization Preparatory Commission has agreed to restrict gamma-ray spectral measurements during a CTBT on-site inspection to the seventeen activation and fission products listed in Table 1. [5]

\subsection{OsIRIs Design Choices}

An "off-the-shelf" commercial software package would be sufficient for CTBT on-site gamma-ray spectroscopy, except it may reveal the gammaray peaks of other radioisotopes beyond the seventeen listed in Table 1. In addition, all of the commercial spectroscopy packages we are aware of display actual spectra to users during data acquisition and analysis. An experienced spectroscopist can identify the gamma-ray peaks of other radioisotopes visually, even when not flagged by the software.

Instead of commercial software, we adopted and modified the data acquisition and analysis software of the Portable Isotopic Neutron Spectroscopy (PINS) prompt gamma-ray neutron activation analysis system [6] for OsIRIS. PINS was developed at Idaho National Laboratory for on-site inspections under the Chemical Weapons
Table 1. The CTBT-relevant fission-product isotopes and their half-lives*

\begin{tabular}{lll}
\hline Isotope & Half-life & Parent \\
\hline Ba-140 & 12.79 days & \\
\hline Ce-141 & 32.52 days & \\
\hline Ce-144 & 284.89 days & \\
\hline Cs-134 & 2.062 years & \\
\hline Cs-137 & 30.07 years & \\
\hline I-131 & 8.02 days & 3.204-day Te-132 \\
\hline I-132 & 2.295 hours & 12.79-day Ba-140 \\
\hline La-140 & 1.678 days & \\
\hline Mo-99 & 2.748 days & 64.0-day Zr-95 \\
\hline Nb-95 & 34.97 days & \\
\hline Nd-147 & 10.98 days & 284.89-day Ce-144 \\
\hline Pr-144 & 17.28 minutes & 373.6-day Ru-106 \\
\hline Rh-106 & 29.8 sec & \\
\hline Ru-103 & 39.26 days & \\
\hline Tc-99m & 6.01 hours & \\
\hline Te-132 & 3.204 days \\
\hline Zr-95 & 64.02 days & \\
\hline & \\
\hline
\end{tabular}

${ }^{*}$ R.B. Firestone, Editor, Table of Isotopes, Eighth Edition (New York: Wiley, 1996)

Convention. The PINS software optionally can hide gamma-ray spectra from users, presenting only summary information. For OsIRIS, hiding gamma-ray spectra is not optional-it is mandatory, and instead of displaying spectra like Figure 2, the display presents only summary information on CTBT-relevant radioisotopes, as shown in Figure 3. 


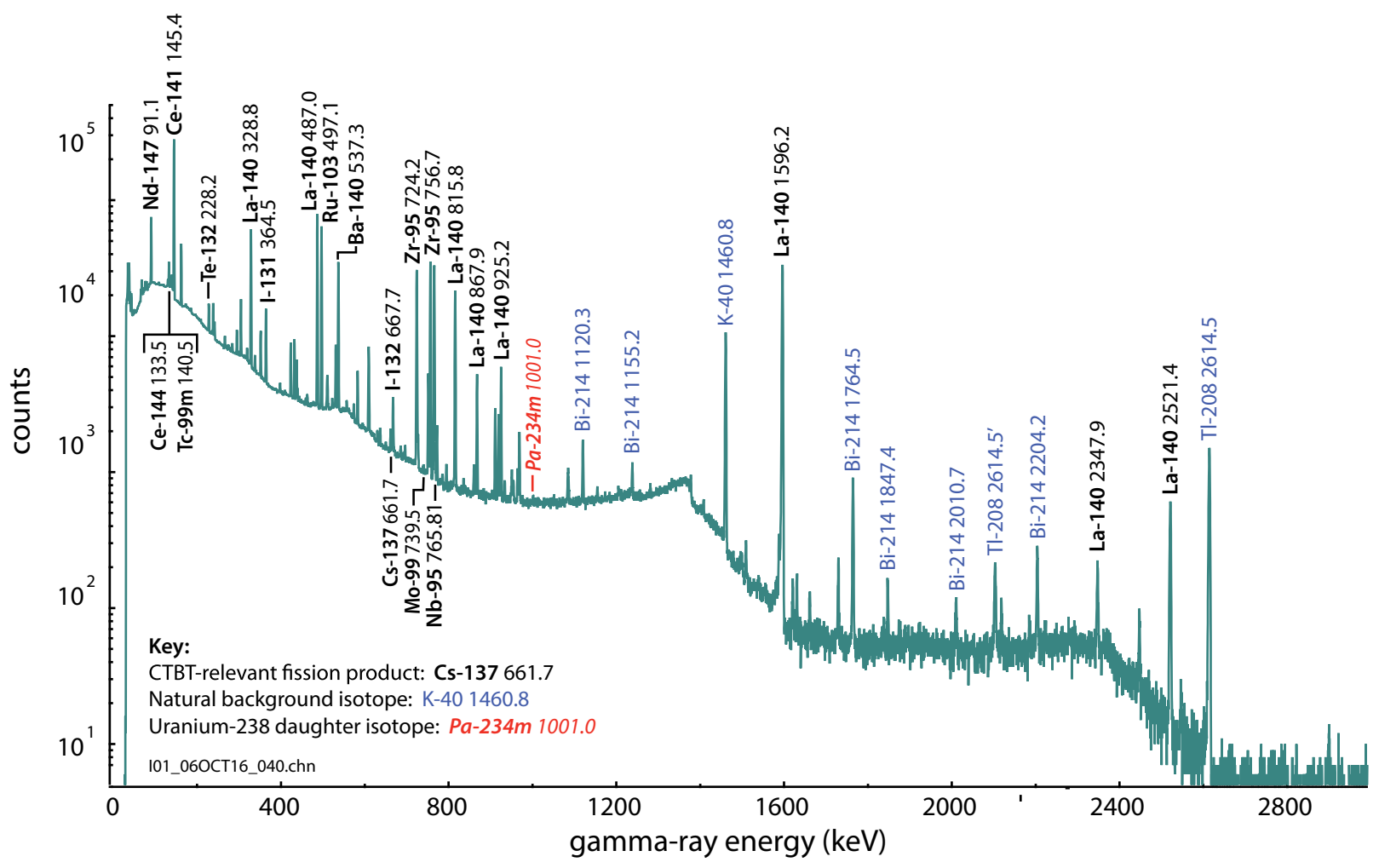

Figure 2. Fission-product gamma-ray energy spectrum, measured from a uranium sample irradiated in the INL Advanced Test Reactor.

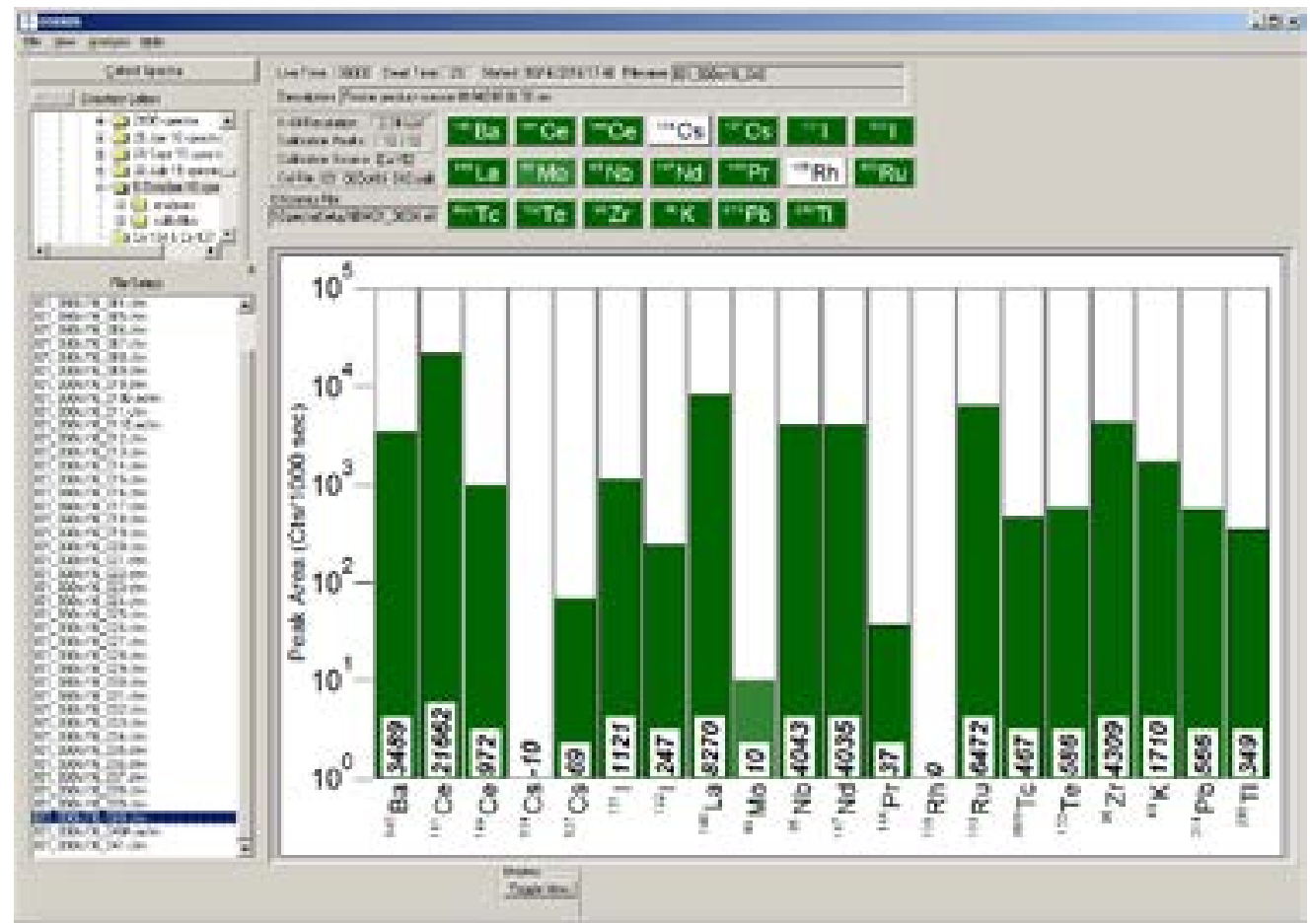

Figure 3. Osiris main radioisotope display 
The complexity of fission-product gammaray spectra requires the use of a high-purity germanium (HPGe) detector to resolve closely-spaced gamma-ray peaks. It is likely that on-site inspections under the CTBT will take place in remote locations, where access to liquid nitrogen and even electricity may be limited. Accordingly, we have chosen a batterypowered, mechanically-cooled HPGe gamma-ray spectrometer also used in some versions of the PINS system.

\subsection{Technology Readiness Level Goal}

The OsIRIS project goal is the development of a commercially-available gamma-ray spectrometer, at Technology Readiness Level (TRL) 8. [7] At the beginning of OSIRIS development, the hardware and software components adapted from PINS were at TRL- 9, corresponding to systems that have been used successfully in military field applications.

\subsection{Performance Metrics}

In addition to restricting spectral information to the seventeen CTBT-relevant isotopes, the following metrics are used to evaluate OsIRIS system performance:

- Detection of the CTBT-relevant fission-product isotopes actually present in a spectrum (high true-positive fraction).

- Non-detection of the CTBT-relevant fissionproduct isotopes not present in a spectrum (low false-positive fraction).

- Correct areas for the CTBT-relevant peaks truly present in the spectrum. The radioactivity, in becquerels or microcuries, of an isotope is directly proportional to its gamma-ray peak area.

- Accurate spectrometer energy calibrations.

- Stable spectrometer electronic gain between energy calibrations. 


\section{OsIRIs Hardware}

The principal OsIRIS hardware components are an HPGe gamma-ray spectrometer and a notebook computer for control, data acquisition, and data analysis.

\subsection{Prototype Gamma-Ray Spectrometer}

The ORTEC Transpec-100 gamma-ray spectrometer was selected as the OsIRIS prototype because of its proven reliability, freedom from liquid nitrogen supplies, battery operation, and $40 \%$ relativeefficiency Ge detector. The Transpec-100 and the nearly identical ORTEC Detective-100 [8] gammaray spectrometers have been used in U.S. military applications since 2005 . The Transpec-100 Ge crystal is cooled to about $100 \mathrm{Kelvin}\left(-173^{\circ} \mathrm{C},-279^{\circ} \mathrm{F}\right.$.) by an internal electrically-powered refrigerator.

The Transpec-100 lithium-ion battery can power the instrument for 12 hours. The Transpec-100 also includes a built-in digital-signal-processing multichannel analyzer.

The Transpec-100 was used at the Comprehensive Nuclear-Test-Ban Treaty Organization Integrated Field Exercise (IFE14) conducted in Jordan during November-December 2014. [9] The spectrometer was used in the in-situ tripod-mounted counting geometry during IFE14, as shown in Figure 4.

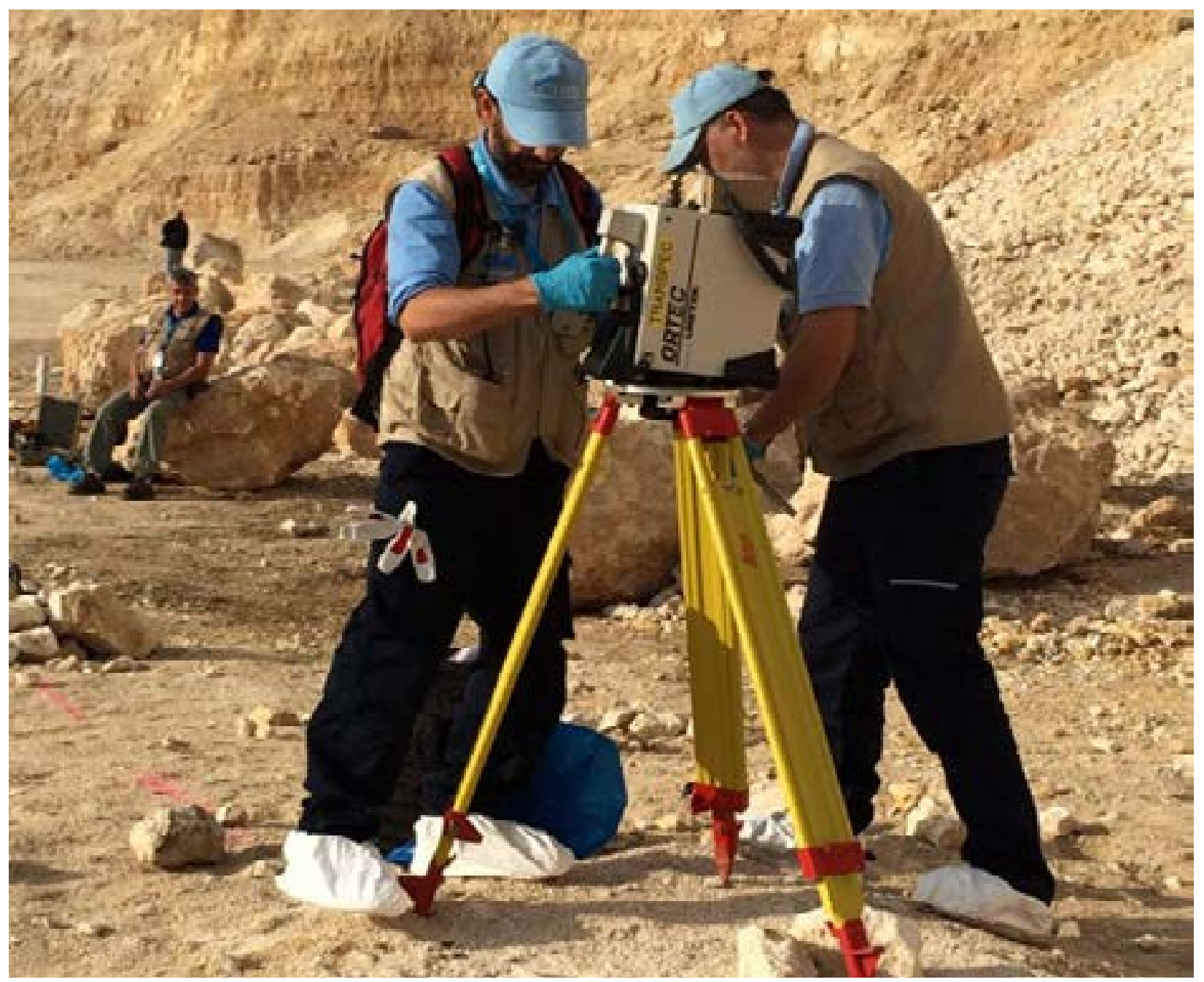

Figure 4. The Transpec-100 gamma-ray spectrometer is set up for in-situ geometry counting in Jordan during the IFE14 CTBTO exercise. 


\subsection{Gamma-Ray Spectrometer Upgrade}

A modified ORTEC IDM-200-V HPGe spectrometer, displayed in Figure 5, replaced the Transpec-100 in 2016 to upgrade spectral data security. Like the Transpec-100, its energy resolution at $1332 \mathrm{keV}$ is $2.3 \mathrm{keV} \mathrm{FWHM}$ or less, and its relative efficiency is higher, $50 \%$. Both the Transpec-100 and the IDM employ the same digital-signal-processing electronics.

However, a standard IDM retains the most recent gamma-ray spectrum in internal memory, even when powered off, and available for download on another computer. To preclude this mode of data loss, OsIRIS IDM spectrometers have been factory modified to erase the gamma-ray spectrum in internal memory whenever the USB cable is disconnected from the control computer.

The IDM spectrometer features are summarized in Table 2.

\subsection{Control Computer}

The OsIRIS control computer is a ruggedized notebook computer, running the Microsoft Windows operating system. It communicates with the spectrometer via USB cable. For data security reasons, this cable must not be disconnected while the spectrometer is counting gamma rays.

The computer controls the spectrometer. It also analyzes, displays, and stores gamma-ray spectral data, as explained below.

\subsection{Auxiliary Equipment}

The OsIRIS systems also include a tripod for measurements using the in-situ geometry, shown above in Figure 4, a source holder for sample measurements, shown in Figure 6, military-grade external lithium batteries and charger for field operation away from AC line power, and three custom foam-lined shipping containers.

Table 2. OSIRIS gamma-ray spectrometer features [10]

\begin{aligned} Model: & ORTEC Interchangeable Detector Module IDM-200-V \\ \hline HPGe crystal material: & p-type \\ \hline Relative efficiency: & $50 \% \\$\hline Energy resolution: & $<2.3 \mathrm{keV} @ 1332 \mathrm{keV}$ FWHM \\ \hline Multichannel analyzer (MCA): & built-in digital-signal-processing MCA, $16 \mathrm{~K}$ channels \\ \hline Dimensions: & $16.3 \times 13.4 \times 8.4$ inches $(41.3 \times 34.0 \times 21.2 \mathrm{~cm}) \\$\hline Weight: & 39 pounds ( 18 kilograms) \\ \hline Input power: & 30 watts when cold \\ \hline Internal battery life: & 2.5 hours \\ \hline External battery: & extends operating life to 8 - 10 hours; hot-swappable \\ \hline Cool-down time: & 15 hours from room temperature \end{aligned}




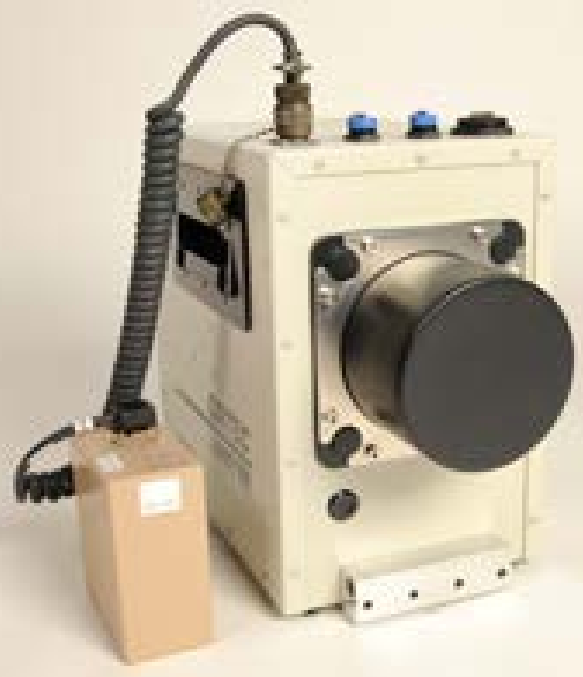

Figure 5. ORTEC IDM-200-V gamma-ray spectrometer and external battery.

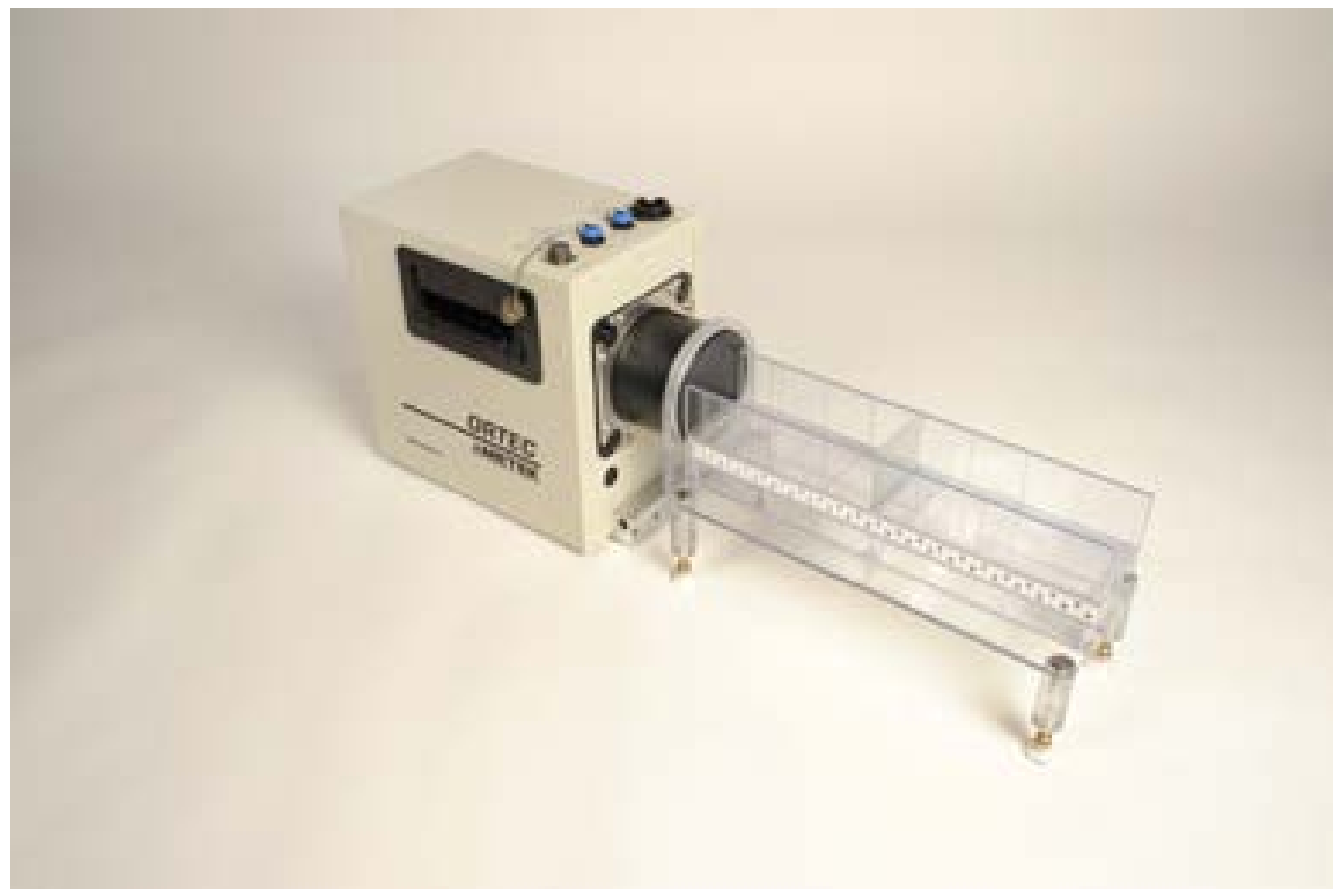

Figure 6. IDM spectrometer and source holder 


\section{OsIRIS Software}

\subsection{Data Acquisition Software}

The spectrometer is controlled from the computer using ORTEC CONNECTIONS low-level commands. However, users never see that complexity, and the graphical-user interface guides the operator through startup, data collection, and shutdown.

At startup, the user-friendly checklists guide the operator through the initialization steps, in proper order, as shown in Figure 7. Initialization includes setting multichannel analyzer parameters, enabling detector high voltage, and performing a spectrometer pole-zero cancellation. Next the operator is instructed to calibrate the spectrometer energy and peakwidth scales, using a gamma-ray check source, typically Eu-152.

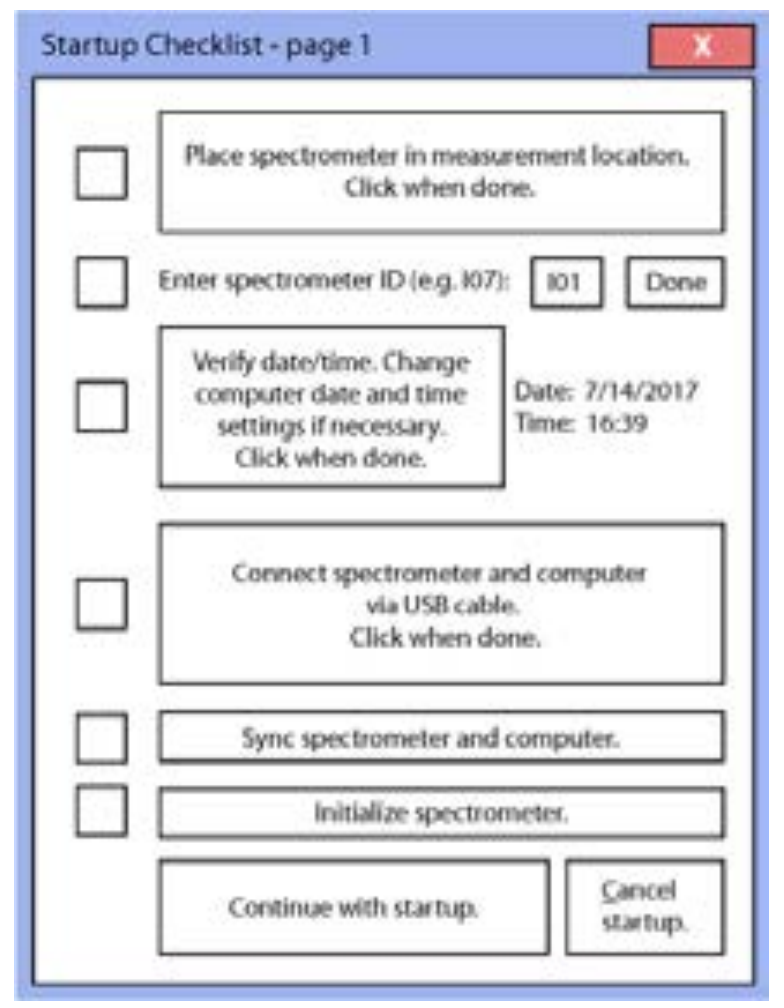

Prior to spectral data collection, the operator presets the measurement live time. Controls are provided to start and stop data collection, and to extend live time, if desired. During data acquisition, the spectrum is analyzed and the information display is updated every 10 seconds. At the end of data acquisition, the raw spectrum is encrypted, as explained in section 3.6, and saved along wih an open (non-encrypted) summary data analysis file.

The spectrometer is shutdown via another checklist.

\subsection{Spectral Analysis}

Spectroscopy is the art of measuring and interpreting wavelength-intensity or energyintensity patterns, or "spectra."

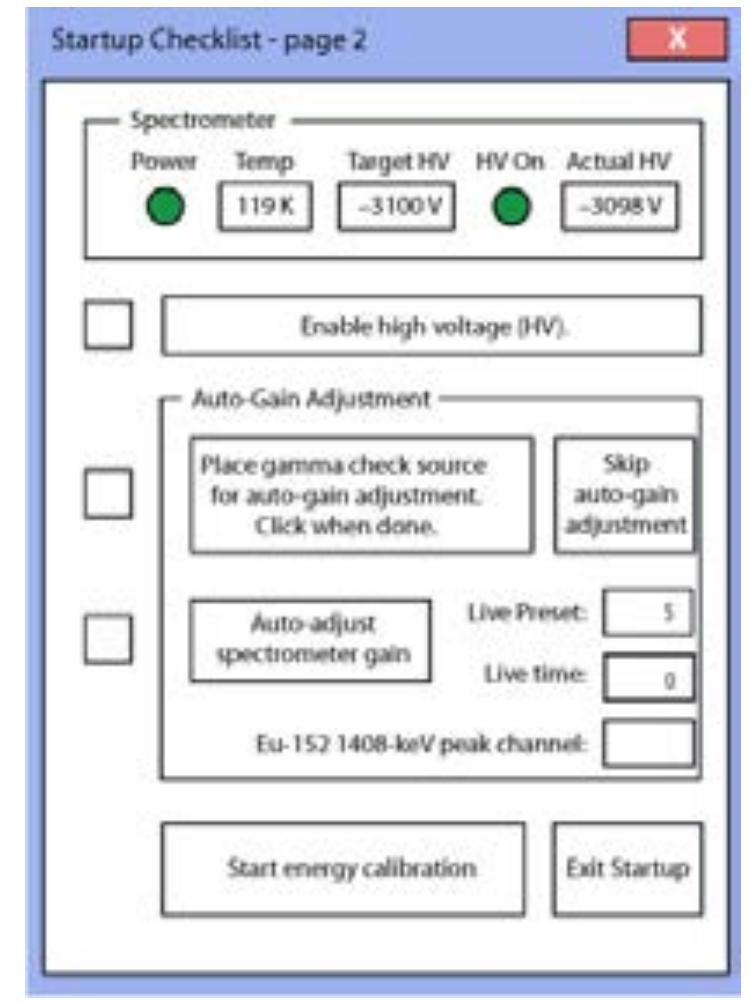

Figure 7. Startup checklist pages. 
Each OsIRIS spectrum, like that displayed in Figure 2, may contain over 100 vertical spikes or peaks, and these peaks are the keys to its interpretation. A gamma-ray peak has several notable attributes, as depicted in Figure 8 . The most obvious feature is the peak height above background. The centroid, the midpoint of the peak's count distribution, determines the energy of the gamma-ray peak. The energy of a gammaray peak identifies the emitting radioisotope, in this instance $\mathrm{Cs}-137$. Hence, determination of gamma-ray peak energies is critical for correct interpretation of spectra. In this report, gammaray energies are stated in kiloelectron volts (keV).

The width of a gamma-ray peak, usually measured as the full width at half maximum (FWHM) peak height, is an important measure of gamma-ray detector performance. When an HPGe gamma-ray detector begins to fail, the first sign is often increased peak widths in spectra. In addition, an unusually wide peak may indicate the presence of two adjacent gamma-ray peaks that cannot be resolved by the spectrometer.
OsIRIS displays the width of the K-40 natural background peak at $1461 \mathrm{keV}$, permitting operators to check this indicator of spectrometer performance.

By summing the area under the peak and above the background, one determines the net peak area in counts. In turn, the net peak area is proportional to the activity of the emitting radioisotope, as measured in becquerels or microcuries.

\subsubsection{Spectral Analysis Logic}

The OsIRIS spectral analysis software supervisory logic is shown in Figure 9. Following initialization and energy calibration, a gamma-ray spectrum is acquired. Next a peak search is performed, and based on the detected and required peaks, the peak-fitting regions are determined. After region-by-region peak fits, the radioisotopes evident in the spectrum are identified by peak energy and the corresponding peak areas and uncertainties noted. For peak detection, OsIRIS currently requires the peak area to exceed the peak background uncertainty by a factor of 3 or

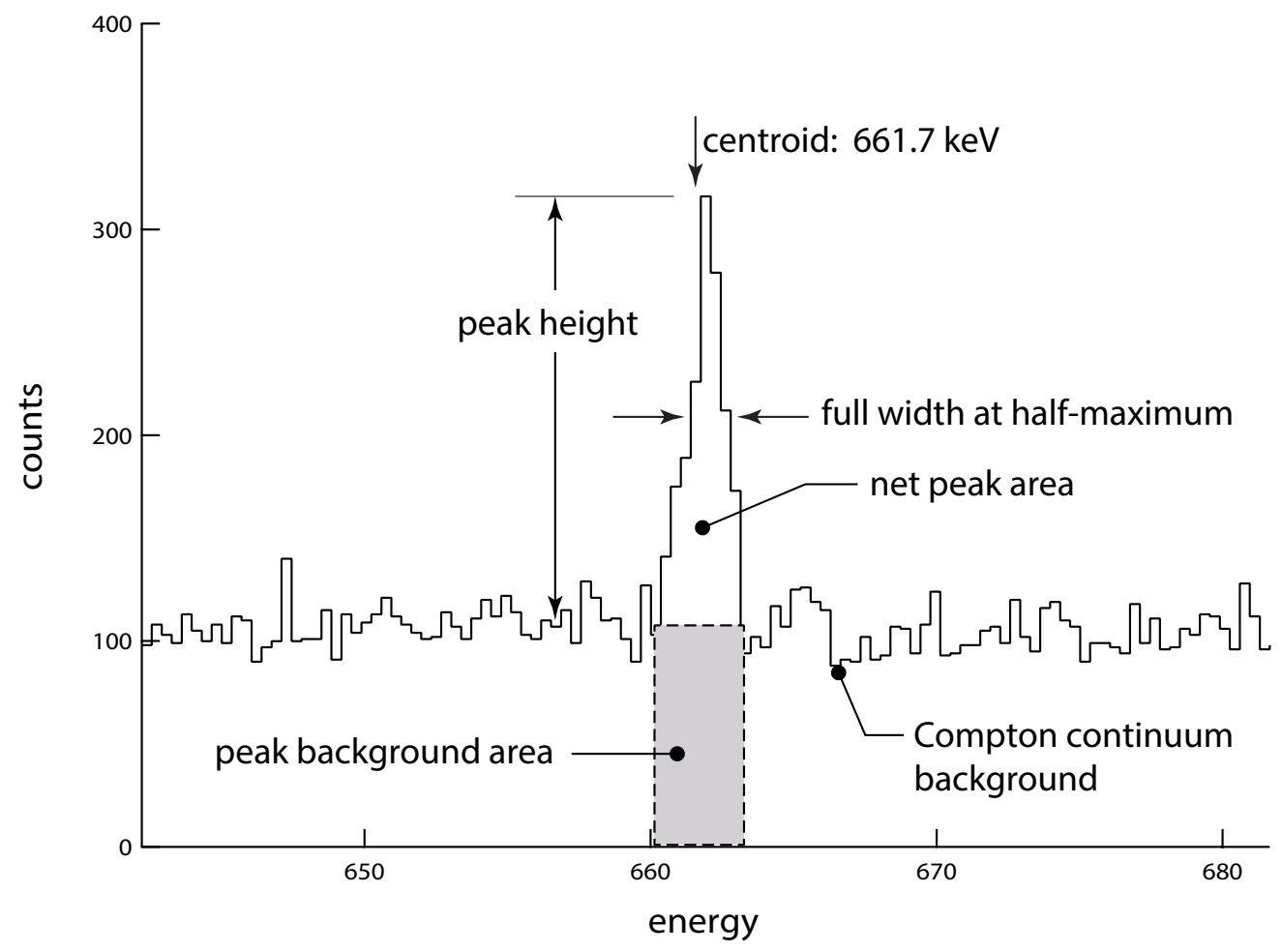

Figure 8. Gamma-ray spectral peak features. 
more. Finally, information on the treaty-relevant fission products is pushed across the data filter for display to the user.

\subsubsection{Nonlinear Least-Squares Peak Analysis}

OsIRIS spectral gamma-ray peaks are characterized with the GAUSS gamma-ray spectrum analysis algorithms of Helmer and McCullagh. [11] GAUSS peak analyses use nonlinear least-squares fits

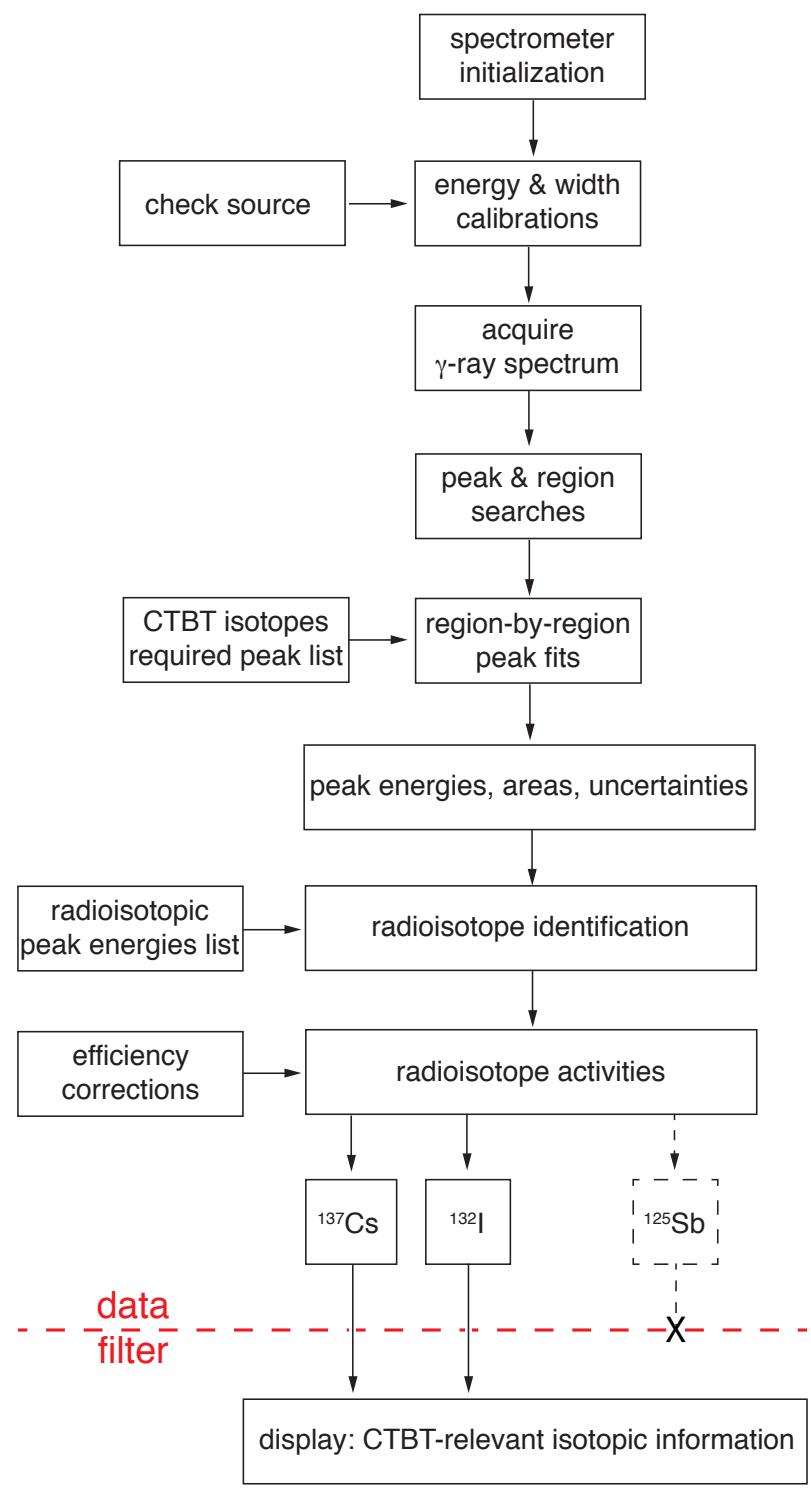

Figure 9. Spectral analysis software supervisory logic to spectral peaks. This peak analysis method is especially suitable for complex fission-product spectra.

Figure 10 displays a GAUSS fit of overlapping peaks in the 650- to $680-k e V$ region of a nuclear reactor fuel-sample spectrum. Note that GAuss determines both net peak areas, as indicated by the blue shading of the Cs-137 peak, and the centroid energies, as the arrow in the $1-132$ peak demonstrates. Also note that GaUss correctly fits the overlapping I-132 and Sb-125 peaks.

Most of the critical fission-product gamma-ray energies and intensities used in the OSIRIS code are taken from the 1988 textbook of Debertin and Helmer. [12] The isotope half-lives, and the remaining gamma-ray energies and intensities are from the 1996 Table of Isotopes, Eighth Edition. [13]

\subsubsection{Automated Spectrometer Calibration}

The spectrum analysis algorithms rely on accurate calibration of the spectrometer energy scale. For example, the isotope Cs-137 is identified by a gamma-ray spectral peak at $661.7 \mathrm{keV}$. If the spectrometer energy calibration was just $1 \%$ too high, this peak would be misidentified as the 667.7-keV I-132 peak. (Both peaks can be seen in Figure 10.) However, with care, it is possible to calibrate HPGe spectrometers to $0.05 \%$ accuracy.

In our experience, energy calibration of a gammaray spectrometer can be somewhat difficult for technician-level operators. Hence, we adapted the PINS automatic energy-calibration for use with the OsIRIS system. Using a Eu-152 or Th-228 microcurie-strength check source, a good energy calibration can be achieved in 100 seconds. OsIRIS systems can also be calibrated using natural background gamma rays, but the process requires a 1,000-second count.

A spectrum-blind system like OSIRIS is nearly impossible to energy calibrate, even for experienced spectroscopists, without some type of computer assistance. 
The OSIRIS automatic energy calibration algorithm is described in detail in an earlier report. [14]

\subsection{Initial Tests of OsIRIS Software}

The OSIRIS software was tested with both measured and synthetic fission-product spectra.

\subsubsection{Reactor Fuel-Sample Spectra}

Seven fission-product spectra from irradiated uranium were analyzed. These spectra were measured from experimental uranium nuclearreactor fuel samples irradiated in the Idaho National Laboratory (INL) Advanced Test Reactor. The cooling times after irradiation prior to measurement varied from 6 to 24 months. The fission-product gamma-ray peaks are quite intense in these spectra, and since the spectrometer was shielded and tightly collimated, most of the natural background peaks are not evident.

\subsubsection{Synthetic Test Spectra}

Eight on-site inspection scenarios were defined to design a set of synthetic gamma-ray spectra for OSIRIS data analysis assessment. The scenarios were as follows:

1. Underground nuclear explosion - strong activity, including particulates release at surface, assayed 4 weeks after explosion.

2. Underground nuclear explosion - weak activity, with limited particulate release at surface, assayed 4 weeks after explosion.

3. Underground nuclear explosion - weak activity, with limited particulate release at surface, assayed 1 year after explosion.

4. Underground nuclear explosion - gas-only release at surface with subsequent decaydaughter particulate deposition, assayed 4 weeks after explosion.

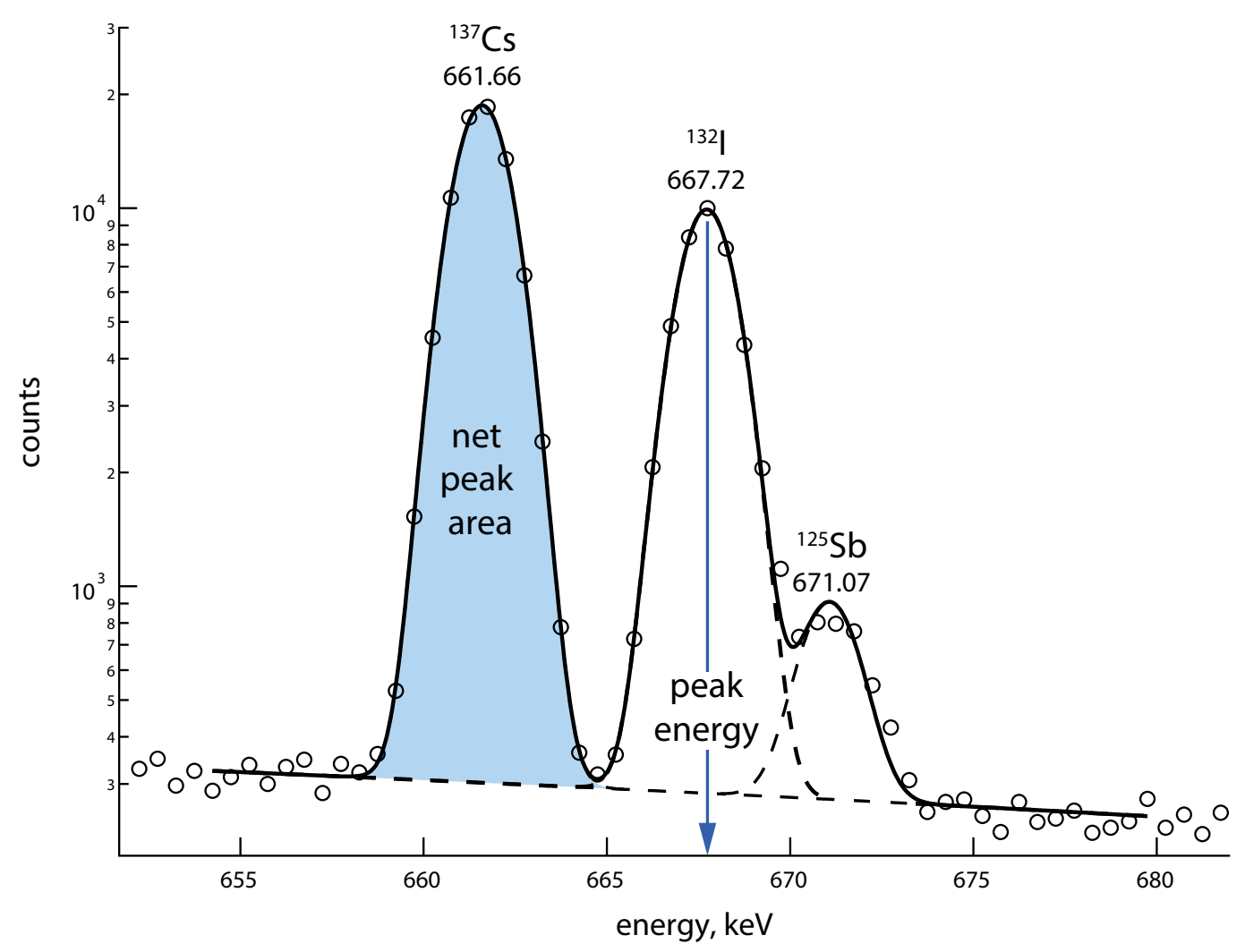

Figure 10. GAUSS nonlinear least-squares fit to three fission-product gamma-ray peaks. 
5. Legacy test-site contamination surface debris and gas seepage assayed decades after explosions.

6. Reactor accident - predominantly volatile release, like the Fukushima, Japan reactor accident, assayed 3 weeks after the accident.

7. Reactor accident - core release with refractories \& volatiles, akin to the Chernobyl, Ukraine reactor accident, assayed 2 days after the accident.

8. Spent-fuel reprocessing waste site radioactivity emissions.

Of these, the first four scenarios are not compliant with the Comprehensive Nuclear-Test-Ban Treaty (CTBT) while the latter four are treaty-compliant.

The synthetic spectra were based on actual measured spectra, to the extent possible, but often computer simulations were necessary to combine the fission-product signal with a naturalbackground gamma-ray spectrum. As necessary, the synthetic gamma-ray spectra were generated using the Los Alamos MCNP code [15] and the PNNL SYNTH code. [16] In total, this test set contains 100 individual synthetic spectra.

In all cases, the spectra were analyzed twice, once by an experienced spectroscopist using the GAUSS XI interactive gamma-ray spectral analysis program, and once by the OSIRIS automated software. The two analyses were compared and scored by a computer program.

\subsubsection{Spectrum Analysis Test Results}

The performance of the OsIRIS spectrum analysis software in the tests described above is summarized in Table 3. The OsIRIS spectrum analysis software and the spectrum analysis test are described further in a Nuclear Instruments and Methods in Physics Research A article. [17]

\subsection{Radioactivity Determination}

The radioactivity (activity, for short) $A$ of an isotope is calculated from the net area $N$ of its spectral peak at energy $E$ :

$$
A=N /(f \cdot \eta(E) \cdot T),
$$

where $f$ is the gamma-ray emission fraction, $\eta(E)$ is the absolute detection efficiency at the energy of the gamma-ray peak, and $T$ is the live counting time. The activity calculation is the final step in gamma-ray spectral peak analysis.

The counting time is reported, to millisecond accuracy, by the spectrometer. Each emission fraction is tabulated in reference books like the Table of Isotopes.

The detection efficiency of an HPGe detector is a function of the detector crystal size and shape, the counting geometry, and the gamma-ray energy. Since HPGe crystals are not manufactured in standard sizes and shapes like scintillation detectors, their detection efficiency must be calculated or measured as a function of

Table 3: Overall OsIRIS correct and incorrect isotope identification scores.

\begin{tabular}{lllll}
\hline Isotope type & $\begin{array}{l}\text { True positive } \\
\text { fraction, \% }\end{array}$ & $\begin{array}{l}\text { True negative } \\
\text { fraction, \% }\end{array}$ & $\begin{array}{l}\text { False positive } \\
\text { fraction, \% }\end{array}$ & $\begin{array}{l}\text { False negative } \\
\text { fraction, \% }\end{array}$ \\
\hline $\begin{array}{l}\text { Treaty-relevant fission } \\
\text { products }\end{array}$ & 98.1 & 96.2 & 3.8 & 1.9 \\
\hline Other fission products & 86.5 & 94.9 & 5.1 & 13.5 \\
\hline Other radioisotopes & 95.0 & 96.8 & 3.2 & 5.0 \\
\hline $\begin{array}{l}\text { Natural background } \\
\text { isotopes }\end{array}$ & 83.5 & 89.7 & 10.3 & 16.5 \\
\hline
\end{tabular}


gamma-ray energy for each HPGe spectrometer and each counting geometry used with that spectrometer. Typically, the efficiency of a spectrometer is characterized when it first arrives from the factory. The initial detection efficiency calibration is usually good indefinitely unless the detector is repaired.

For OSIRIS, three geometries are of interest: pointsource measurements, in-situ geometry counting, and soil-sample measurements.

\subsubsection{Point Source Detection Efficiency}

The detection efficiency for a point source in a given geometry, e.g., $30-\mathrm{cm}$ from the detector face is determined as follows:

- Measure a calibrated gamma-ray point source in the desired geometry.

- A "mixed" isotope source containing, say, Am-241, Cd-109, Co-57, Co-60, and Y-88 is preferable to a single-isotope source emitting multiple gamma-rays, like Eu-152.
- Determine the net peak areas in the recorded spectrum using a general purpose spectral analysis program like ORTEC MAESTRO. [18]

- Correct the calibration-day activities for the decays of the source isotopes since the source calibration date.

- Calculate the detection efficiency $\eta(E)$ at each mixed-source gamma-ray energy:

$\eta(E)=N(A \cdot f(E) \cdot T)$, where $N$ is the net peak area, $f(E)$ is the emission probability for a gamma-ray of energy $E$ (some sources emit more than one gamma ray), and $T$ is the measurement live time.

- Fit a polynomial curve through the measured data points. INL uses a cubic-spline curve, calculated with the MATLAB program. [19]

- Provide the efficiency curve coefficients to OsIRIs in a text file.

The detection efficiency curve for a point source $30 \mathrm{~cm}$ from an OsIRIS spectrometer front face is shown in Fiqure 11.

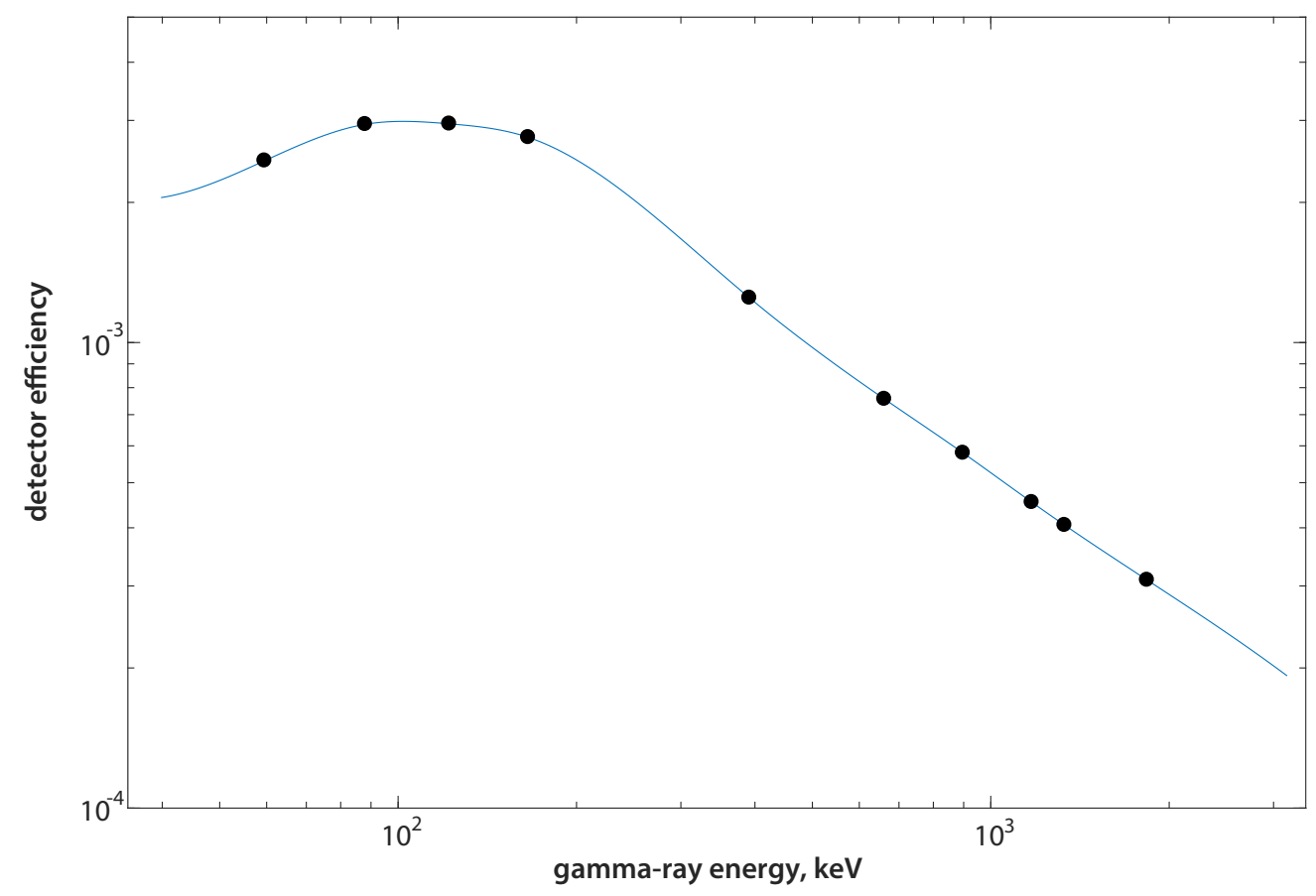

Figure 11. Point-source detection efficiency at $30 \mathrm{~cm}$. 


\subsubsection{Detection Efficiency for In-Situ Counting}

The in-situ gamma-ray counting method was designed to permit environmental radioactivity measurements over a broad area with little or no need to collect soil samples. [20] In this counting geometry, the HPGe detector is mounted on a tripod, nose down as shown in Figure 12, with the front surface of the HPGe crystal $100 \mathrm{~cm}$ above the ground.

A series of detailed Monte Carlo studies, supplemented by gamma-ray measurements, has produced the calibration curve displayed in Figure 13 for an IDM spectrometer used in the in-situ geometry. This curve has a $10 \%$ uncertainty. Remarkably, the Monte Carlo studies indicate that gamma rays from as far away as 70 meters make a significant contribution to an in-situ geometry measurement, and even gamma rays from activity about 500 meters away contribute to the spectrum.

For example, if Cs-137 is distributed uniformly on an infinite flat plane in air (no surface roughness), its 662-keV gamma rays, having have a meanfree-path length of 104 meters (1/e ) in air at STP, produce these spectral effects in an IDM-200 spectrometer $100 \mathrm{~cm}$ above the ground:

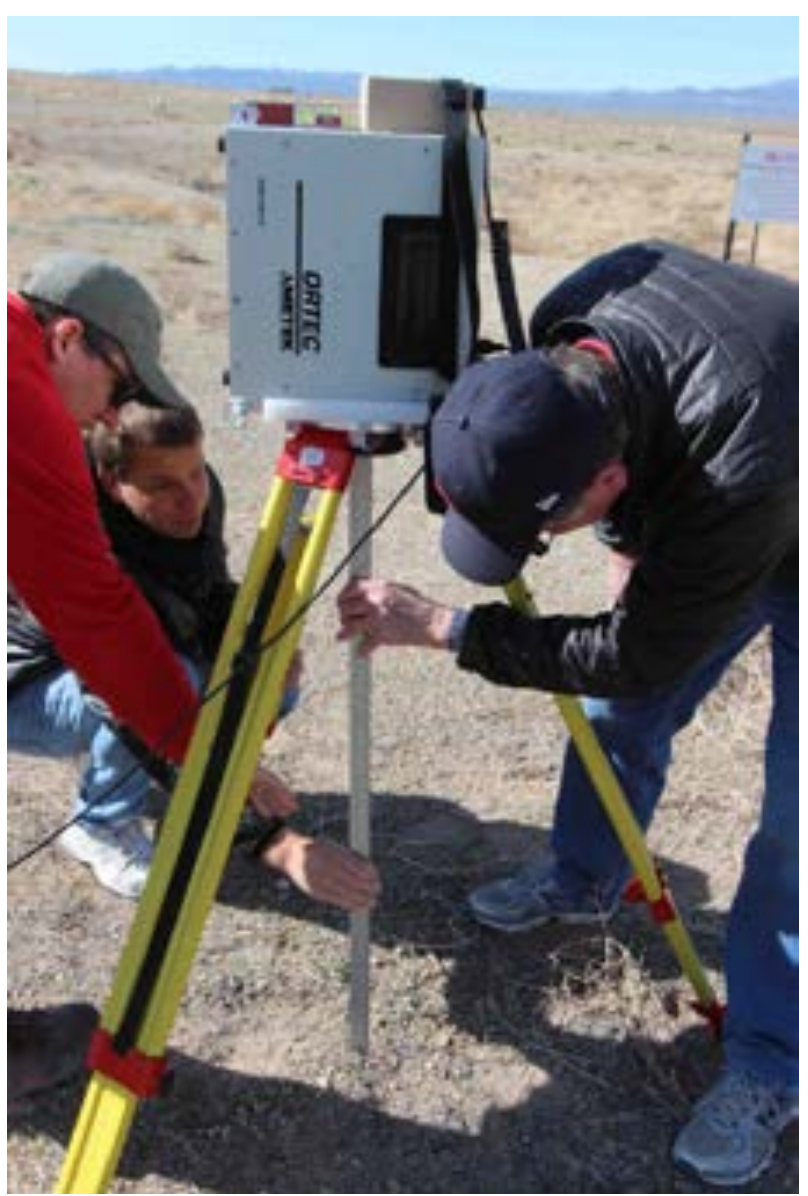

Figure 12. INL and PNNL physicists adjust the height of an OSIRIS spectrometer for in-situ measurements.

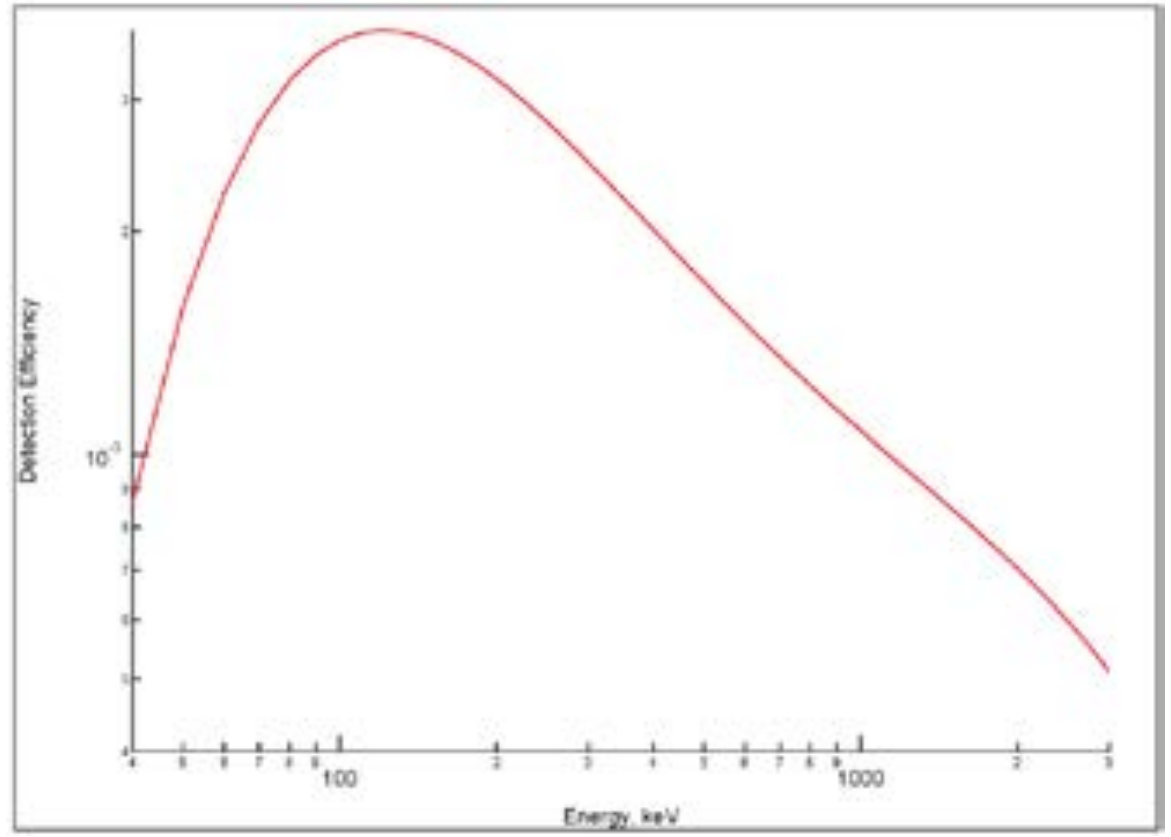

Figure 13. OSIRIS in-situ geometry detection efficiency. 
- $57 \%$ of the full-peak count rate comes from inside the 10-meter radius (and 43\% from outside 10 meters)

- $90 \%$ within a $68-$ meter radius

- $99 \%$ within a $214-$ meter radius

What maximum radial distance is needed for this Monte Carlo calculation? At 3,000 keV, $99 \%$ of the full-peak count rate comes from within a 440-meter radius, probably a sufficient radial distance cut-off in the Monte Carlo calculations. For the in-situ efficiency curve as displayed in Figure 13, the solution was calculated out to a radius of $1000 \mathrm{~m}$ for 0-3,000 keV. Hence, radial truncation at 1 kilometer produces less than a $1 \%$ truncation effect, well within the estimated $10 \%$ uncertainty envelope.

\subsubsection{Soil-Sample Detection Efficiency}

The detection efficiency for gamma-ray peaks depends on a variety of parameters, such as detector size, source location, source composition, and source geometry. Figure 14 shows the modeled peak efficiency for an OSIRIS detector for three different sources, a container with soil in which the radioisotopes distributed uniformly, an empty container with the radioisotopes distributed uniformly and a point source. The center of all three sources is at the same location, equivalent to $1 \mathrm{~cm}$ distance between the nearest sources of the detector and the container. The plot shows the impact of solid angle, going from the point source to the distributed source, as well as the impact of the soil attenuation going from the distributed source to the soil source. These differences motivate a different approach for conducting detector efficiency measurements for a soil sample.

The recommended approach to determine the peak efficiencies for a soil sample is inspired by the semi-empirical approach of Huy et al. [21], which performs an efficiency measurement on a soil sample of known composition and known activity which is then corrected based on radiation transport modeling results. The primary difference between our approach and that of Huy et al., is a simplified correction for energy and density. With this simplified correction, it is estimated that the uncertainty of the calibration can be determined to $4 \%$ for all energies at and above $125 \mathrm{keV}$, and $9 \%$ at $88 \mathrm{keV}$. The primary contribution to this uncertainty is unknown soil composition. Details of the methodology can be found in [22].

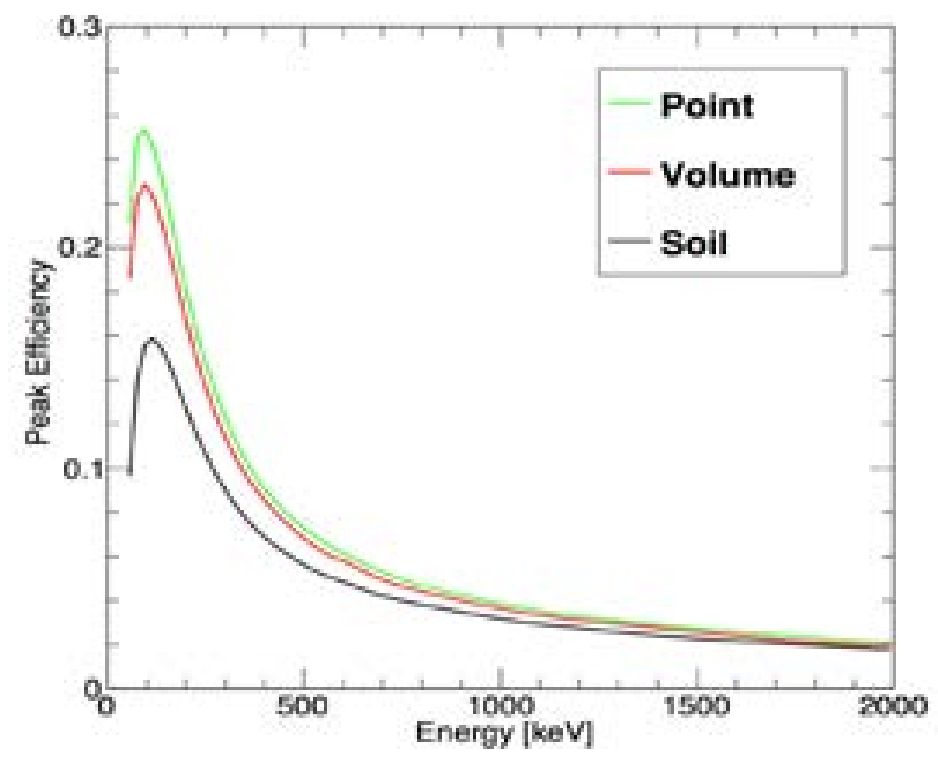

Figure 14. Comparison of peak efficiencies for a variety of sources 
The efficiency calibration approach is to determine the efficiency for an unknown soil sample using a measurement on a known soil sample and a correction factor. For a known container at a fixed distance from the detector, the efficiency of an arbitrary soil sample can be determined based on the efficiency of a calibrated soil sample using

$$
\left.\varepsilon(\rho, E)=\varepsilon_{C}\left(\rho_{C} E\right)\left[1+(0.0827 \ln (E)-0.6629)\left(\rho-\rho_{C}\right)\right]\right)
$$

where $E$ is the energy, $\varepsilon\left(\varepsilon_{c}\right)$ is the efficiency of the (calibration) sample, and $\rho\left(\rho_{c}\right)$ is the density of the (calibration) sample. This relationship holds only when the calibration soil sample and unknown sample are placed in the same type of container and placed at the same distance from the detector. The initial measurements of the calibrated soil sample can be performed either in advance of the field measurements, or in the field if it is possible to transport the radioactive soil sample to the field counting location.

Our detection efficiency calibration procedure for soil samples is as follows:

1. Select a container for the soil samples. The ideal container has a relatively large diameterto-height ratio, with the diameter slightly smaller than the diameter of the detector crystal. The container should be made of low atomic number material to reduce attenuation in the container walls.

2. Select a soil sample to use for the calibration sample. Ideally, the calibration soil would be similar to the soil for the unknown sample. The most important variable is the density of the soil. The unknown soil composition introduces a relatively small uncertainty of 4 to $9 \%$.

3. Select an aqueous calibrated radioisotopic solution. Such solutions can be found from commercial vendors. One typically needs an activity of a few $\mu \mathrm{Ci}$ or less per calibration sample.
4. Measure the density of the calibration soil in the container, $\rho_{s}$.

5. Prepare the calibration soil sample with the radioisotopic solution. Follow appropriate radiation protection procedures. Ensure that the solution is distributed uniformly in the calibration sample and that the container is well-sealed. Allow the solution to evaporate.

6. Measure the mass of the calibration sample again to determine if density has changed. It is critical that the density be measured accurately.

7. Measure the calibrated soil sample in the desired geometry. It is important that the distance between the detector and the sample be the same for both the calibration and unknown samples; it is especially critical very close to the detector. Set the spectrometer lifetime long enough to acquire 10,000 or more counts in each of the gamma-ray peaks of interest.

8. Analyze the gamma-ray spectrum from the source with a general-purpose gamma-ray spectral analysis program like ORTEC MAESTRO [18], and determine the net peak areas of the gamma-ray peaks from the calibration sample, $N_{i}^{C}$. OsIRIS is not suitable for analysis of mixed-isotope calibration source spectra, as it only reports gamma-ray peak areas from the seventeen CTBT fission products.

9. Decay-correct the source isotope calibrated activities to obtain the activities $A_{i}$ on the measurement date.

10. Measure the density of the unknown soil sample, $\rho_{s}$.

11. Determine the detector efficiency $\eta\left(E_{i}\right)$ at each gamma-ray energy $E_{i}$ by the expression $\eta\left(E_{i}\right)=\eta^{C}\left(E_{i}\right) C\left(E_{i}, \rho_{S_{-}}-\rho_{C}\right)$, where the efficiency for the calibration sample is

$\eta^{C}\left(E_{i}\right)=\left(N_{i}^{C}\right) /\left(T A_{i} B_{i}\right)$, 
and the correction for the difference in calibration sample and soil sample densities is $\eta^{C}\left(E_{i}, \rho_{s}-\rho_{C}\right)=1+\left(0.0827 \ln \left(E_{i}\right)-0.6629\right)\left(\rho_{s}-\rho_{C}\right)$.

$T$ is the measurement time and $B_{i}$ is the gamma-ray emission probability or "branching ratio." Note that for the efficiency measurement, only the density of the soil sample is used as input for the efficiency.

12.Apply corrections for coincidence summing if appropriate to the efficiencies. This can be non-trivial, so it is recommended to select isotopes without coincident signatures.

13.Fit a polynomial curve through the efficiency points, to obtain the approximate efficiency as a function of energy, $\eta\left(E_{i}\right)$.

14.Provide the efficiency curve polynomial coefficients to OsIRIS in a text file.

15. Repeat calculation of sample efficiency for each sample with a different density.

\subsubsection{OsIRIS Detection Efficiency Tables}

The OSIRIS software includes a set of detection efficiency tables. The current efficiency table is displayed in the top left corner of the main dataacquisition window. Users must ensure that the correct efficiency table has been selected for the measurement they are about to perform.

\subsection{Spectral Information for Users}

The OsIRIS software filters spectral information measured during an on-site inspection. Only the radioisotopic information needed to conduct the inspection (the "CTBT-relevant radionuclides") is revealed to the user, not the entire gamma-ray spectrum.

\subsubsection{Data Filter}

A notional spectroscopic measurement data filter [23] is depicted in Figure 15. The data filter hardware and software hide full spectral information from users, revealing only treatyrelevant information on its display device.

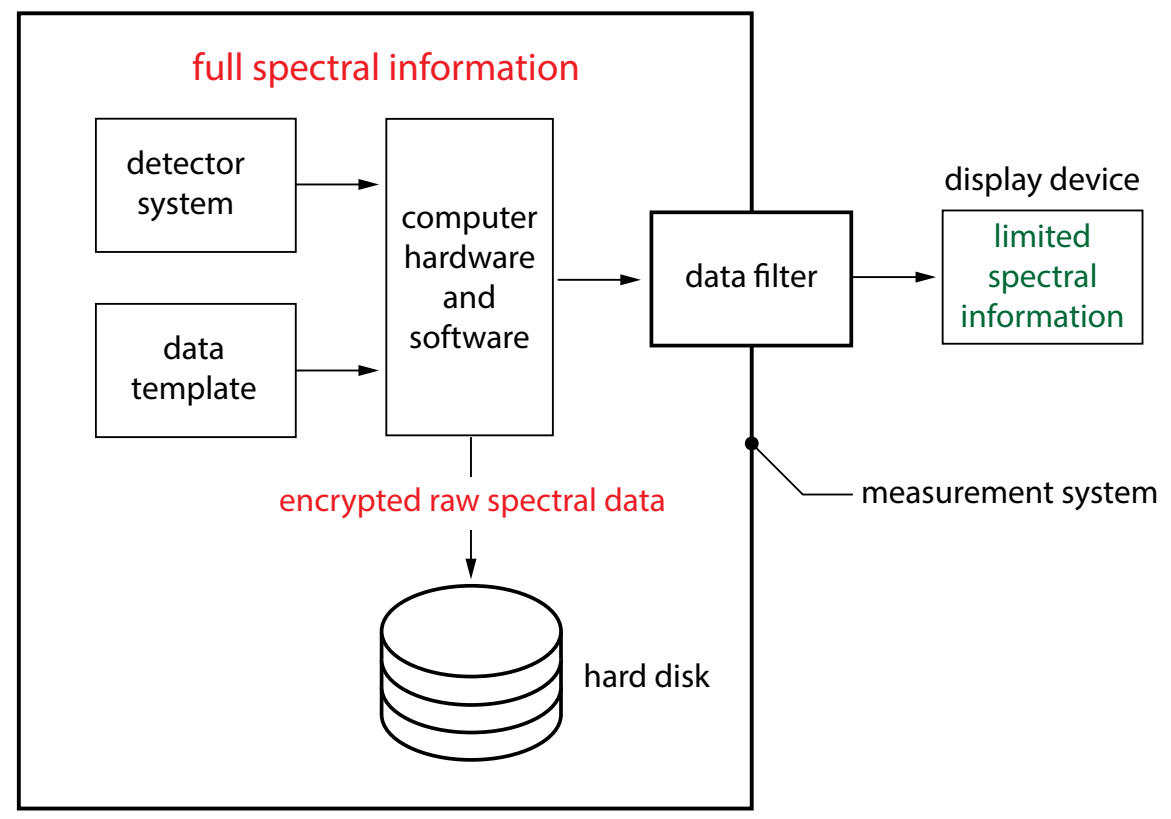

Figure 15. Data filter concept. 


\subsubsection{Bar-Chart Data Display}

The OsIRIS software does not display raw gamma-ray spectra like that shown in Figure 2 to the operator. Instead, the information is limited to radioisotopes relevant to CTBT on-site inspections, and displayed by vertical "intensity bars" as shown in Figure 3. The bar height is proportional to the intensity, in counts/sec, of an isotope's gamma-ray peak.

OsIRIS also provides information on three natural background isotopes sources to assure users the system is operating correctly.

During a measurement, OSIRIS automatically analyzes the input spectral data, updating its analysis every 10 to 15 seconds. The shading of each intensity bar gets darker as detection confidence for the corresponding isotope increases.

\subsubsection{Isotope Information Buttons and Windows}

Above the bar-chart display area in Figure 3, there is a series of buttons, one for each CTBT-relevant isotope. Clicking on a button replaces the bar chart with spectral analysis detail for the selected isotope. Spectral information for the fissionproduct isotope La-140 is shown in Figure 16.

\subsubsection{Data Summary Output File}

A summary of the spectral analysis is stored for each stored gamma-ray spectrum. Unlike the spectrum, the summary text file is not encrypted. The summary data file for the spectrum displayed in Figure 2, measured from a fresh fission-product source, is shown Tables 4-6.

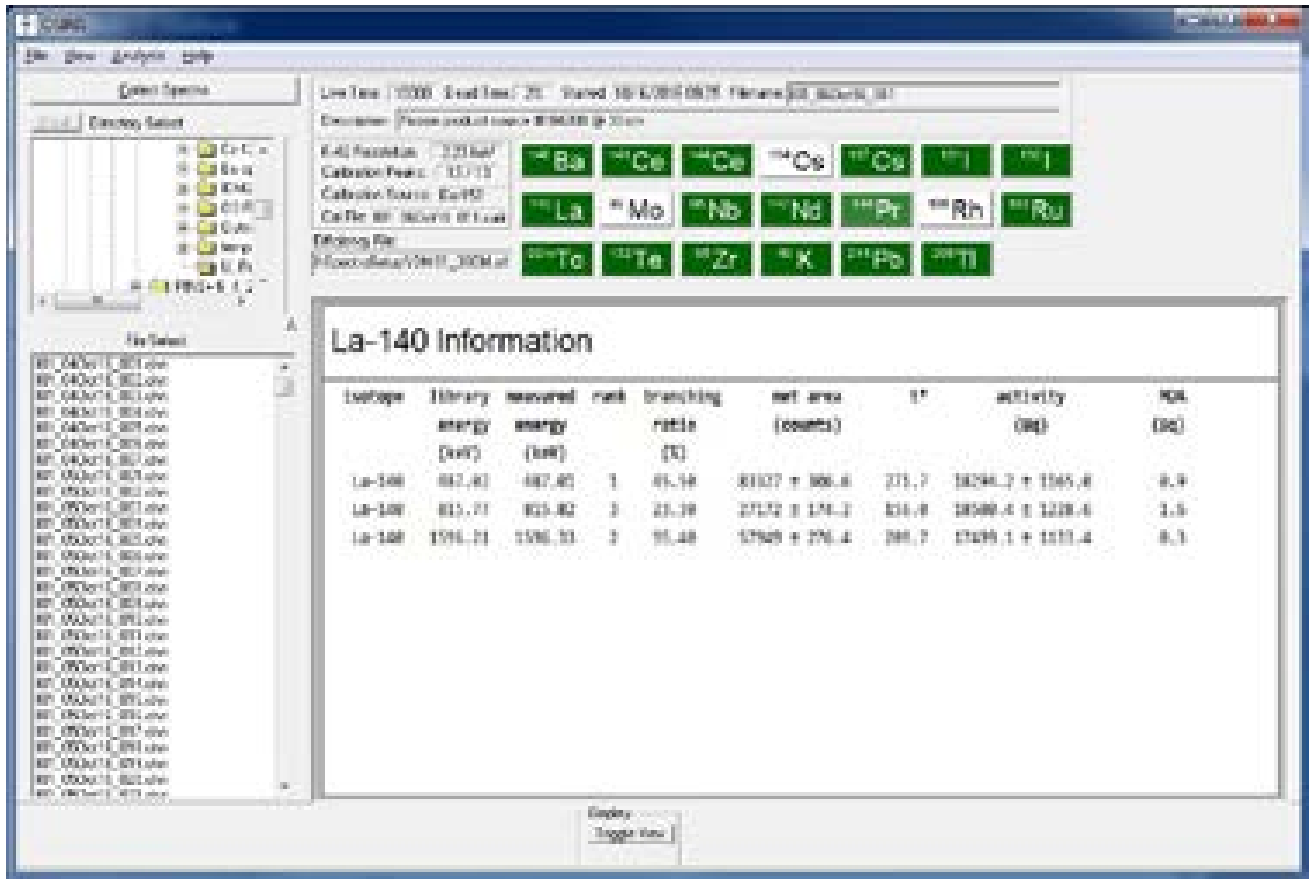

Figure 16. La-140 spectral information window. 
Table 4: Summary Spectral-Analysis Text File

OSIRIS Spectrum-Analysis Summary

File Information

\begin{tabular}{|c|c|}
\hline Spectral Filename & 101_06Oct16_040A \\
\hline Assay Date and Time & 06 October 2016 17:40 \\
\hline Assay Location & PINS Lab \\
\hline Operator & Jayson Wharton \\
\hline Public Key File & $\begin{array}{l}\text { E:\OSIRIS \fission-product spectra \Cs-134 \& } \\
\text { Cs-137 spectra \01_02Jul18_.public }\end{array}$ \\
\hline Sample Description (Header Comments) & Fission product source \#104208@30cm \\
\hline \multicolumn{2}{|l|}{ Spectrometer Description } \\
\hline Spectrometer & IDM-01 \\
\hline HPGe Crystal Temperature & 109 (Kelvin) \\
\hline Live Time (sec) & 39000.08 \\
\hline Dead Time & $2.40 \%$ \\
\hline K-40 Energy Resolution & $2.24 \mathrm{keV}$ FWHM \\
\hline \multicolumn{2}{|l|}{ Analysis Information } \\
\hline Detector Efficiency File & $\begin{array}{l}\text { C:\Program Files (x86)\Osiris 1.7.4\SpectraSetup } \backslash \\
\text { IDM01_30CM.eff }\end{array}$ \\
\hline Gamma-Ray List & LOCKED_IN_CODE \\
\hline Program Version & OSIRIS v1.7.5 \\
\hline \multicolumn{2}{|l|}{ Calibration Information } \\
\hline Calibration File & $\begin{array}{l}\text { E:\OSIRIS\fission-product spectra\6 October } 16 \\
\text { spectra\I01_06Oct16_040.calib }\end{array}$ \\
\hline Energy-Cal Date and Time & 6 October 16 06:32 \\
\hline Energy-Cal Equation & $E(x)=-0.16+0.3654 x+0.000 e+00 x x(k e V)$ \\
\hline Energy-Cal Chi Squared & 0.019000 \\
\hline Energy-Cal Library Peaks & 13 \\
\hline Energy-Cal Peaks Found & 13 \\
\hline Energy-Cal Source & Eu-152 \\
\hline Max Spectrum Energy & 2992.9 (keV) \\
\hline Width-Cal Equation & $W(x)=2.646+0.00098 x($ channels $)$ \\
\hline
\end{tabular}




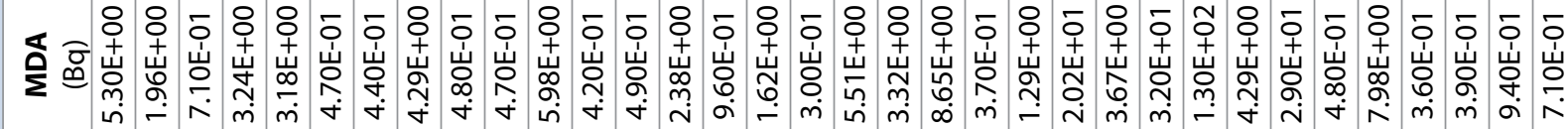

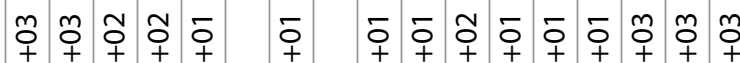

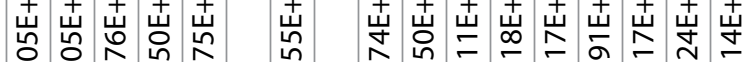

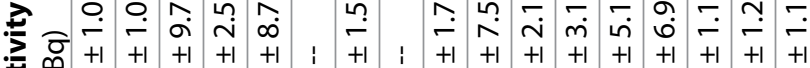

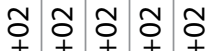

嵌岗嵌岗

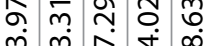

定

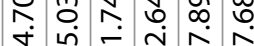

ปี

m $\tilde{o} \tilde{o} \tilde{o} \tilde{o} \tilde{o}$

$+1+1+1+1+1+1$

ठ

嵌岕岕岕岗

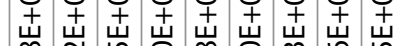

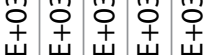

m

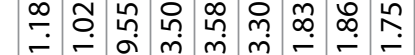

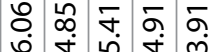

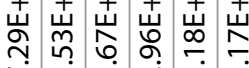

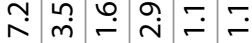

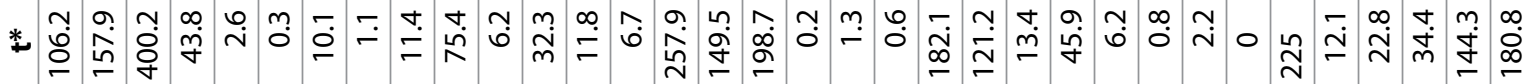

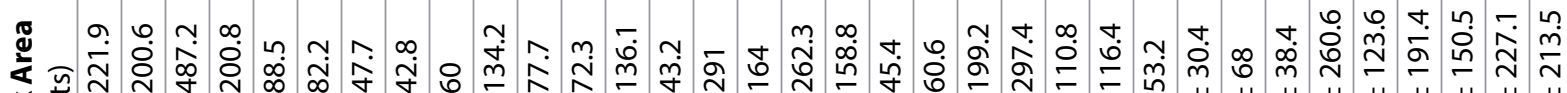

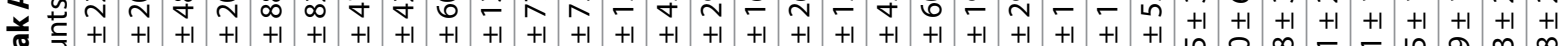
ఏँ

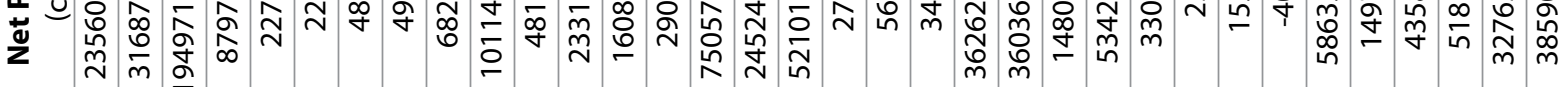

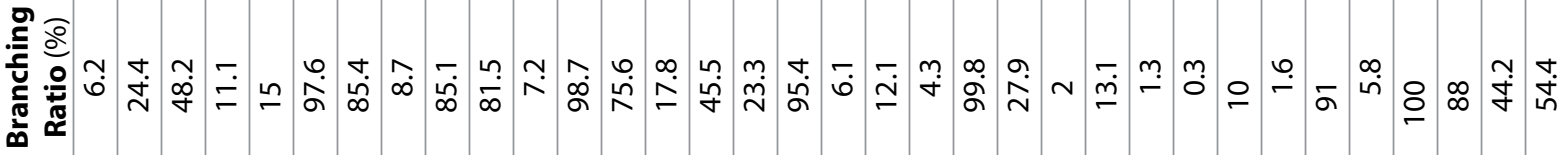

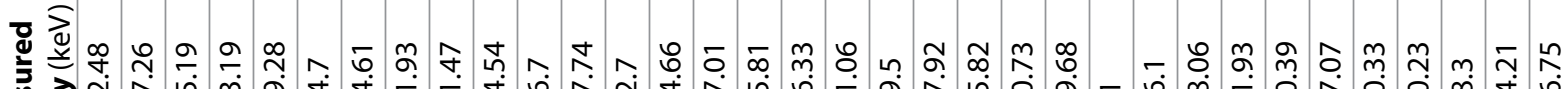

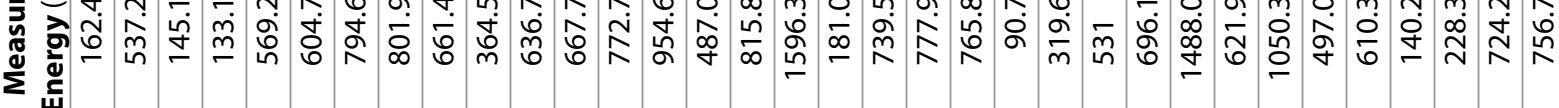

$\widehat{\frac{8}{d}}$

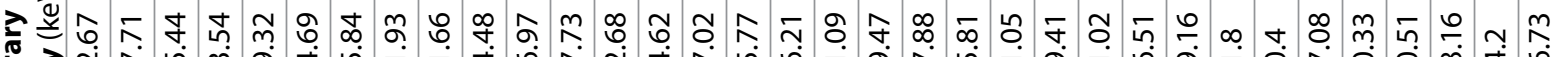

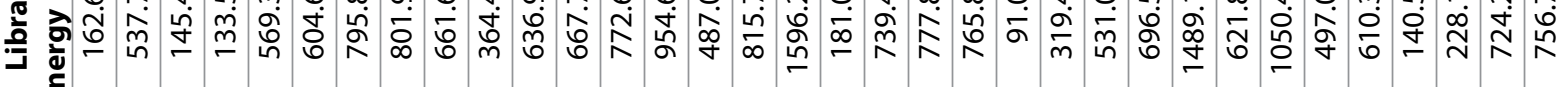

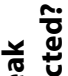

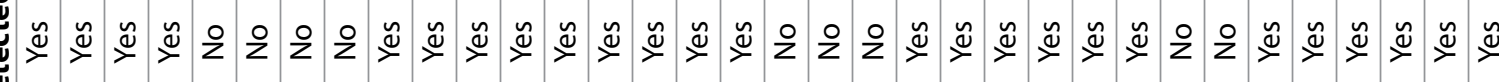

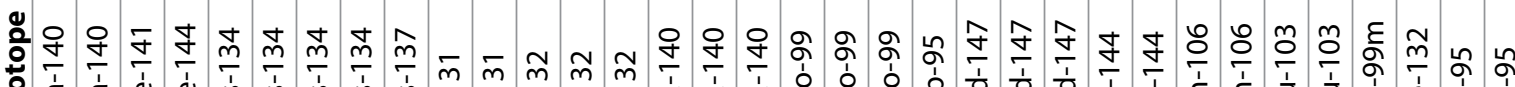

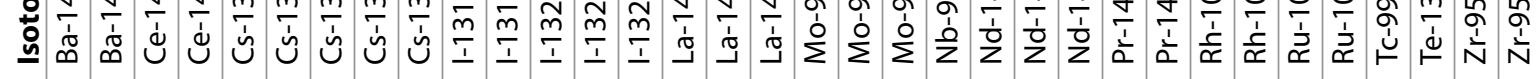


Table 6: Natural Background Isotopic Information

\begin{tabular}{lccccc} 
Isotope & Detected? & $\begin{array}{c}\text { Library } \\
\text { Energy }(\mathrm{keV})\end{array}$ & $\begin{array}{c}\text { Measured } \\
\text { Energy }(\mathrm{keV})\end{array}$ & $\begin{array}{c}\text { Branching } \\
\text { Ratio }(\%)\end{array}$ & $\begin{array}{c}\text { Net Peak Area } \\
\text { (counts) }\end{array}$ \\
\hline $\mathrm{K}-40$ & Yes & 949.83 & 950.93 & 15.0 & $2189.1 \pm 107.3$ \\
\hline $\mathrm{K}-40$ & Yes & 1460.83 & 1460.95 & 10.7 & $66713.0 \pm 276.3$ \\
\hline $\mathrm{Pb}-214$ & Yes & 242.00 & 241.92 & 18.5 & $10860.6 \pm 314.0$ \\
\hline $\mathrm{Pb}-214$ & Yes & 295.22 & 295.18 & 18.2 & $13617.5 \pm 265.3$ \\
\hline $\mathrm{Pb}-214$ & Yes & 351.93 & 351.98 & 35.8 & $22093.7 \pm 242.5$ \\
\hline $\mathrm{Tl}-208$ & Yes & 583.19 & 583.11 & 85.2 & $14915.7 \pm 187.2$ \\
\hline $\mathrm{Tl}-208$ & Yes & 2614.53 & 2614.56 & 99.8 & $13648.8 \pm 127.6$ \\
\hline
\end{tabular}

\subsection{Spectral Data Encryption}

To retain and protect sensitive raw gamma-ray spectra, spectral data is encrypted prior to harddisk storage. Summary analysis information on the seventeen CTBT-relevant isotopes is stored in unencrypted text files. Users have access to the summary spectral information at all times.

OsIRIS encrypts and decrypts spectral data files with the RINJNDAEL block-cipher encryption algorithm of RIJNMEN and DAEMEN. [24] In 2001, this algorithm was selected by the U.S. National Institute of Standards as the Advanced Encryption Standard (AES). [25] OsIRIS employs the AES-128 version using a randomly-generated 128 -bit key for encryption and decryption. The AES-128 encryption key, effectively a password, must be safeguarded, and transmitted in an encrypted mode. OsIRIS uses the Rivest-Shamir-Adleman (RSA) public/private key algorithm to generate and securely transmit encryption keys. [26]

When an OSIRIS spectral file has been decrypted, one would like assurance that the decrypted file matches the original spectral file before encryption. OsIRIS computes a hash, a number somewhat akin to a checksum, before encryption and after decryption, and checks that the hash values match. The operator is warned if the hashes do not match. The OsIRIS hash algorithm is Secure Hash Algorithm-256 (SHA-256), designed by the U.S. National Security Agency. [27] 


\section{OsIRIS System Integration and Testing}

Since gamma-ray spectrometers identify radioisotopes by their associated spectral peak energies, accurate and stable energy calibration is essential for correct isotopic identifications. During an on-site inspection, it is likely OsIRIS will be used outdoors, not in an air-conditioned lab, and it may not be possible to energy-calibrate the instrument every day. Hence, we have tested OsIRIS energy-calibration stability versus both temperature and time.

\subsection{Energy Calibration Stability vs. Temperature}

The OSIRIS spectrometer energy-calibration stability versus temperature was been tested repeatedly in an environmental chamber from $-12^{\circ} \mathrm{C}\left(+10^{\circ} \mathrm{F}\right)$ to $50^{\circ} \mathrm{C}\left(122^{\circ} \mathrm{F}\right)$. The variations of the Eu-152 121-keV and 1408-keV peak-centroid positions vs. temperature, typically less than \pm $0.21 \mathrm{keV}$, are shown in Figure 17.

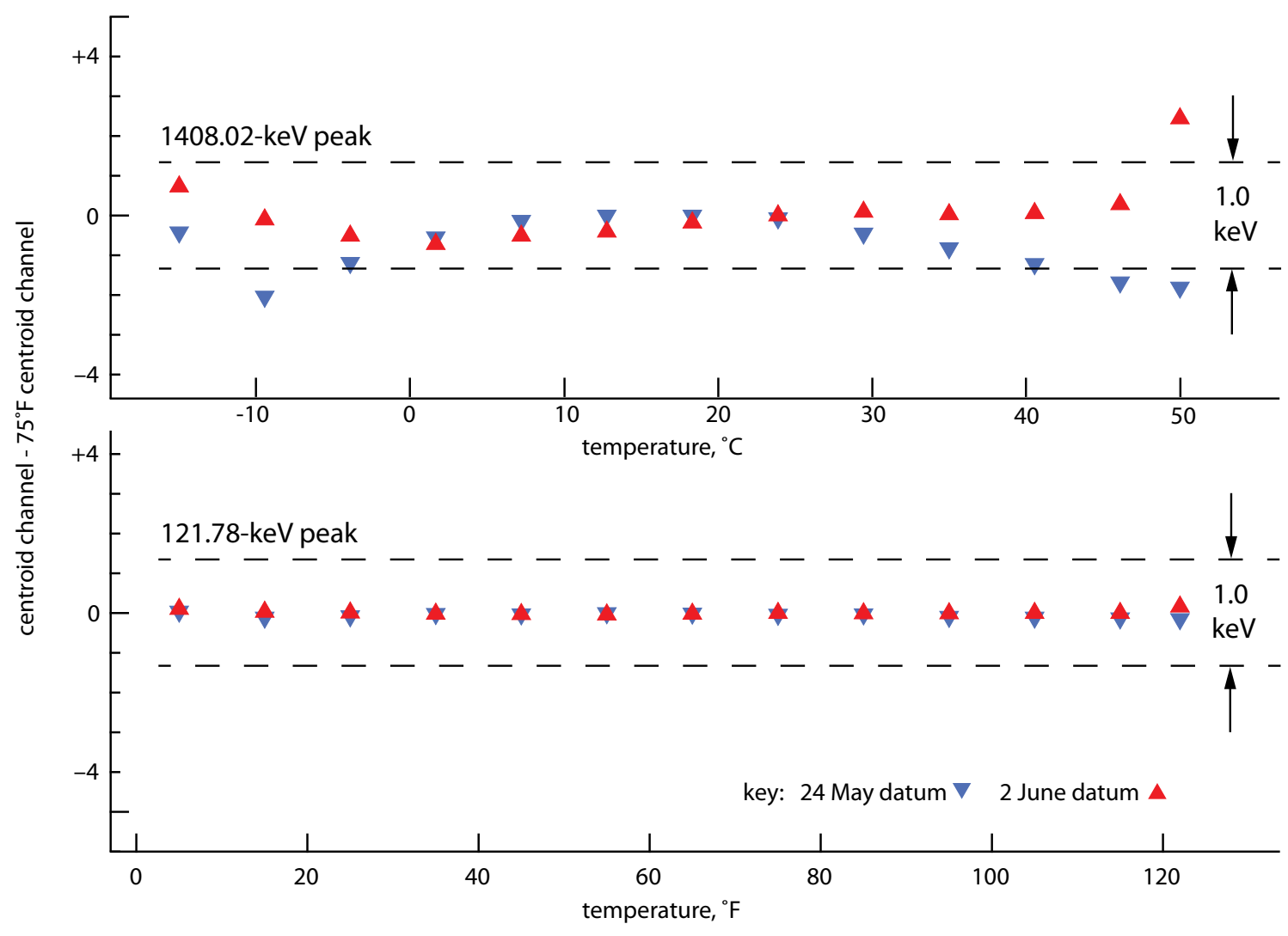

Figure 17. Energy calibration stability vs. temperature. 


\subsection{Energy-Calibration Stability vs. Time}

If a spectrometer is energy-calibrated daily, its calibration must remain stable for at least 24 hours. As a baseline, we first monitored the spectrometer energy-calibration stability indoors, and found it remained stable over 5 days within $0.031 \mathrm{keV}(1 \sigma)$. Next, we conducted month-long tests of the spectrometer outdoors at both Idaho National Laboratory (INL) and Pacific Northwest National Laboratory (PNNL). Testing at INL took place during winter conditions, as shown in Figure 18. The INL winter energy-calibration stability test results are displayed in Figure 19, and the PNNL summer test results are shown in Figure 20. The system energy calibration remained constant within $\pm 0.113 \mathrm{keV}$ in both tests.

\subsection{Cs-134/Cs-137 Ratio}

The ratio of Cs-134 to Cs-137 activity helps differentiate between fission-product spectra produced by a nuclear weapons test, and spectra produced by a nuclear reactor accident or by medical isotope processing. Nuclear explosions do not produce Cs-134, and hence the Cs-134/ Cs-137 activity ratio is zero in fission-product spectra measured after a bomb test. In a nuclear reactor, Cs-134 is produced by thermal neutron capture on stable Cs-133. For example, following the Fukushima Daiichi accident, the Cs-134/ Cs-137 ratio was approximately 1.0. [28]

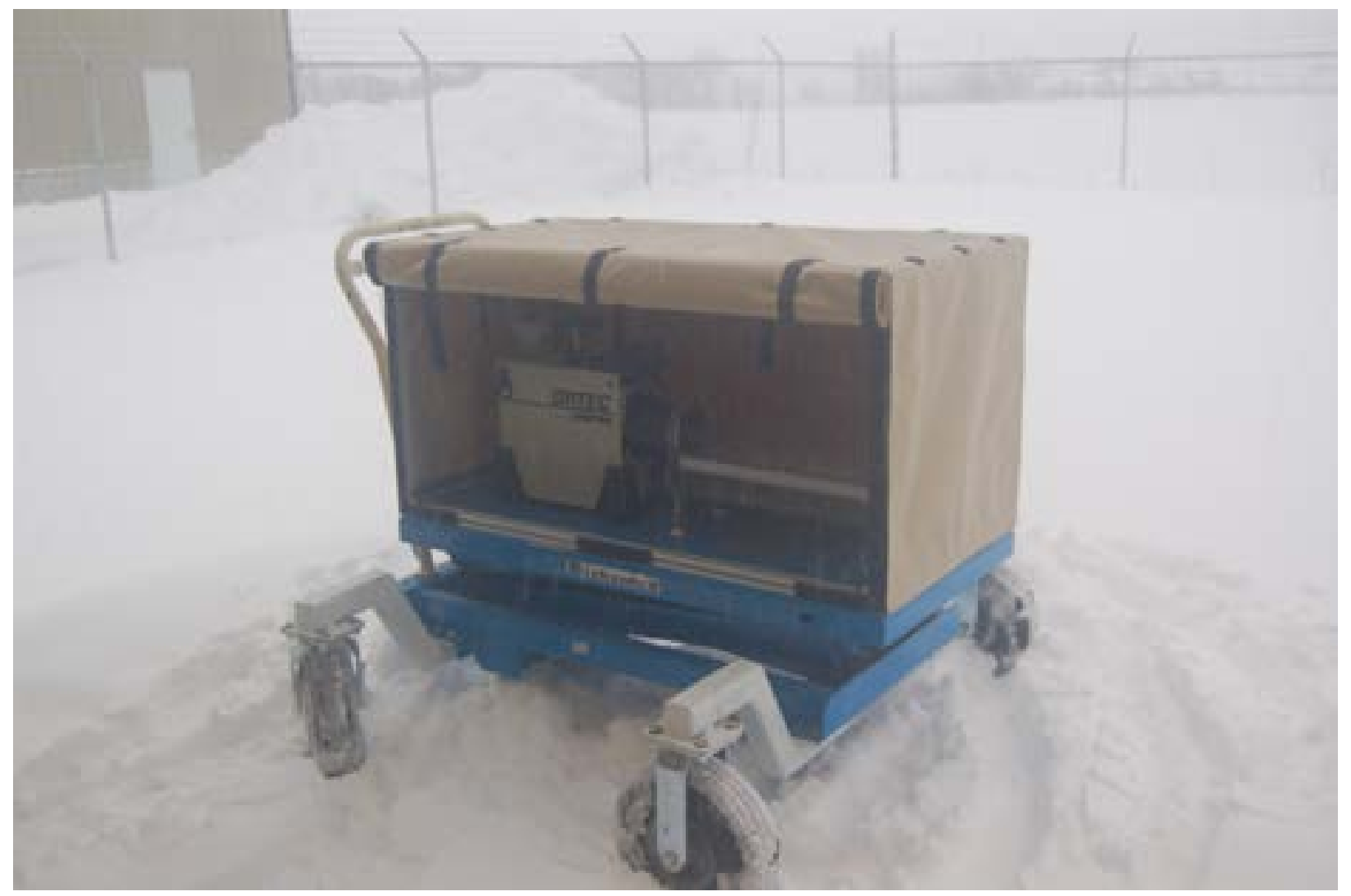

Figure 18. Winter testing of OSIRIS at INL 

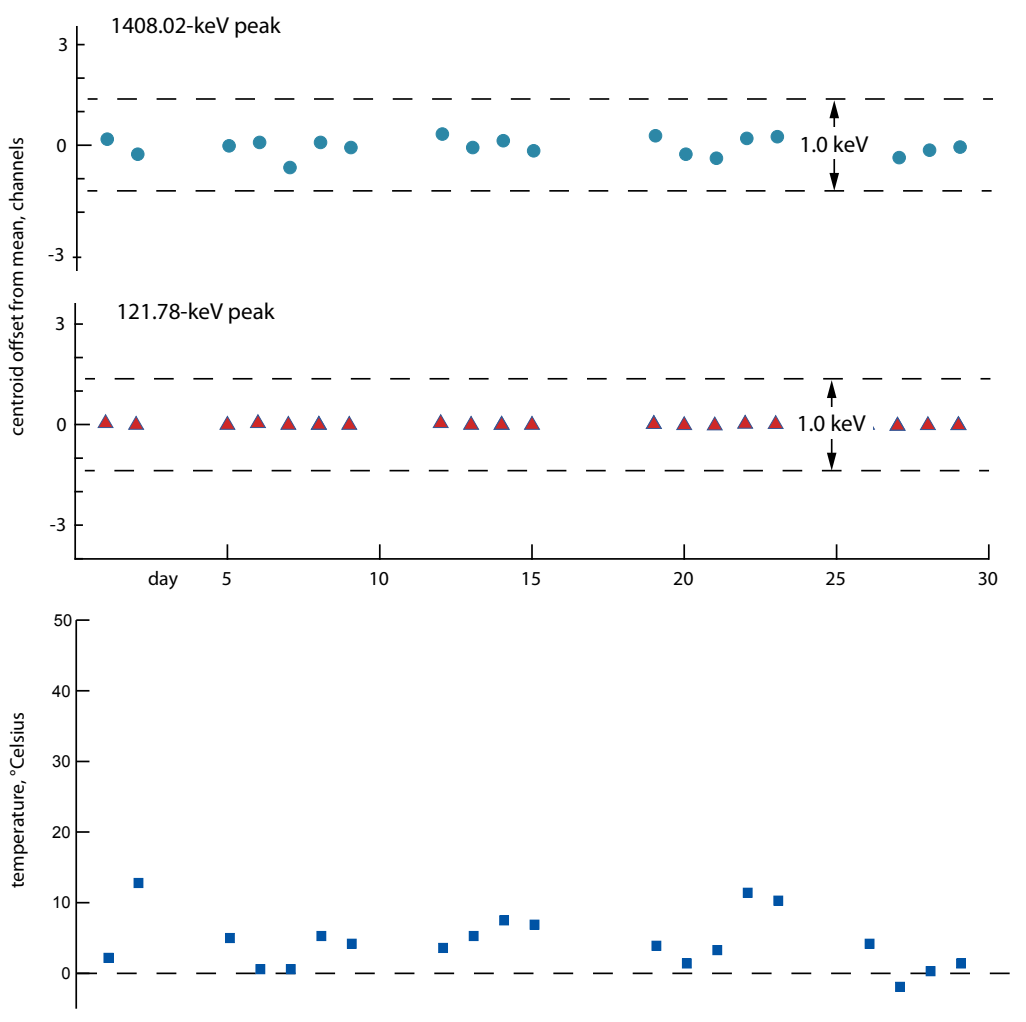

Figure 19. Winter energy calibration stability vs. time.

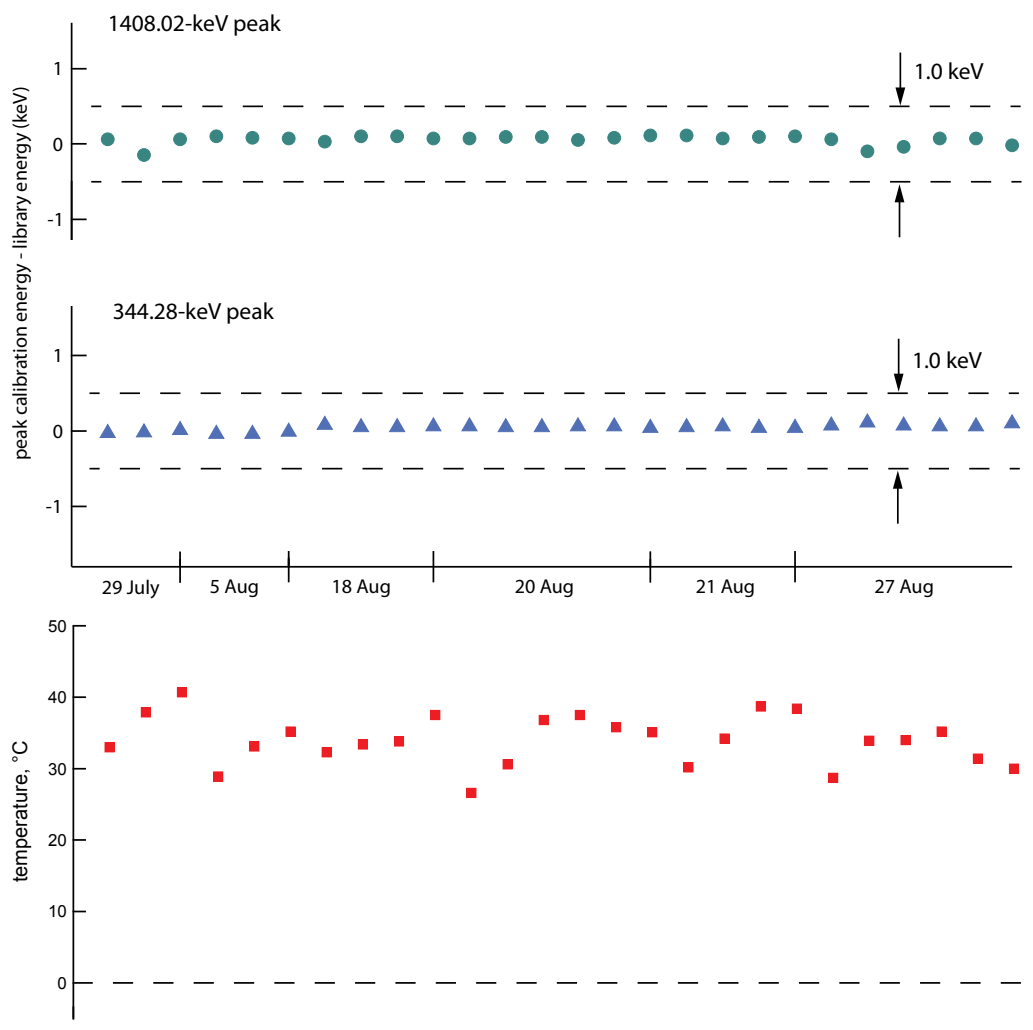

Figure 20. Summer energy calibration stability vs. time. 


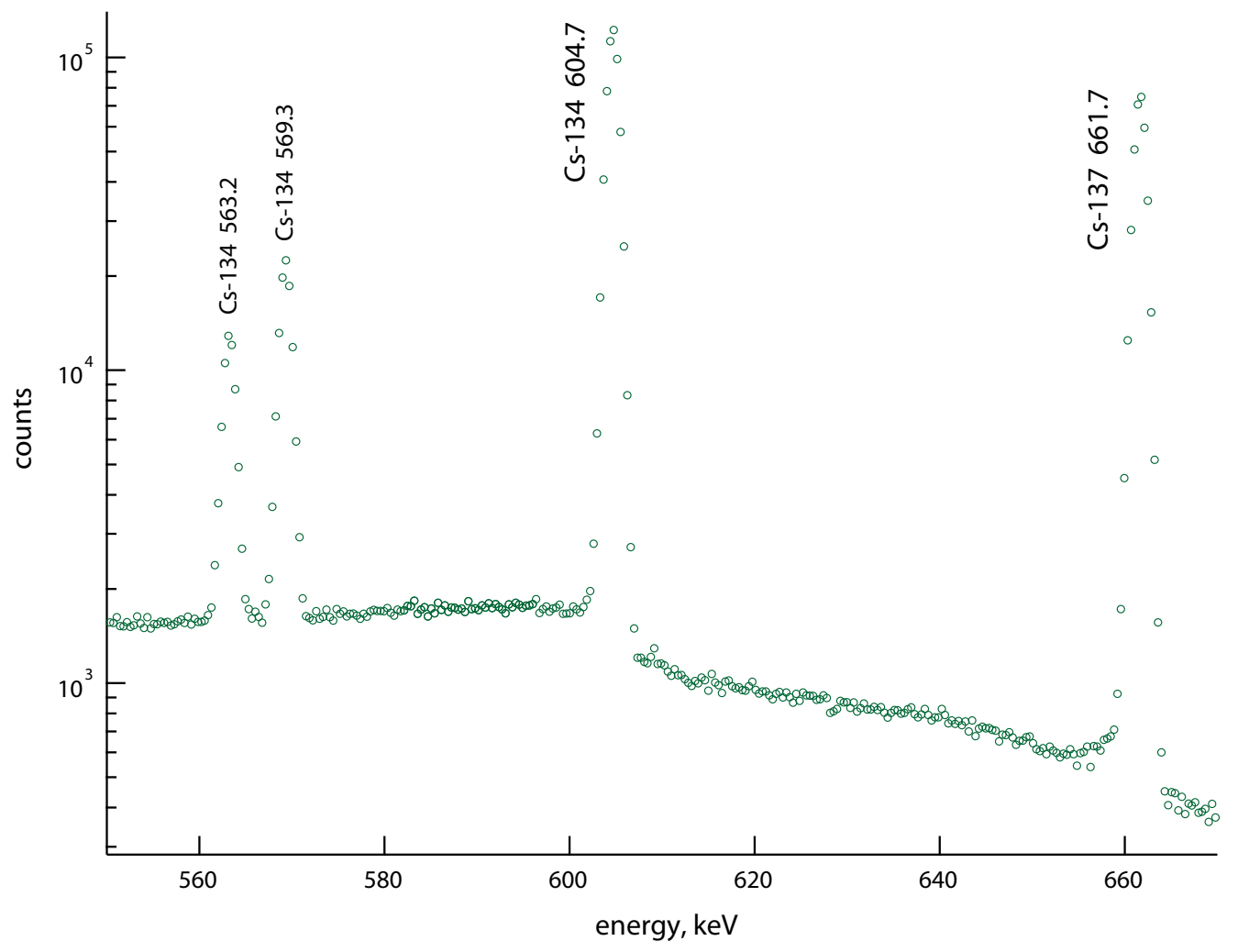

Figure 21. Cs-134 and Cs-137 spectral peaks.

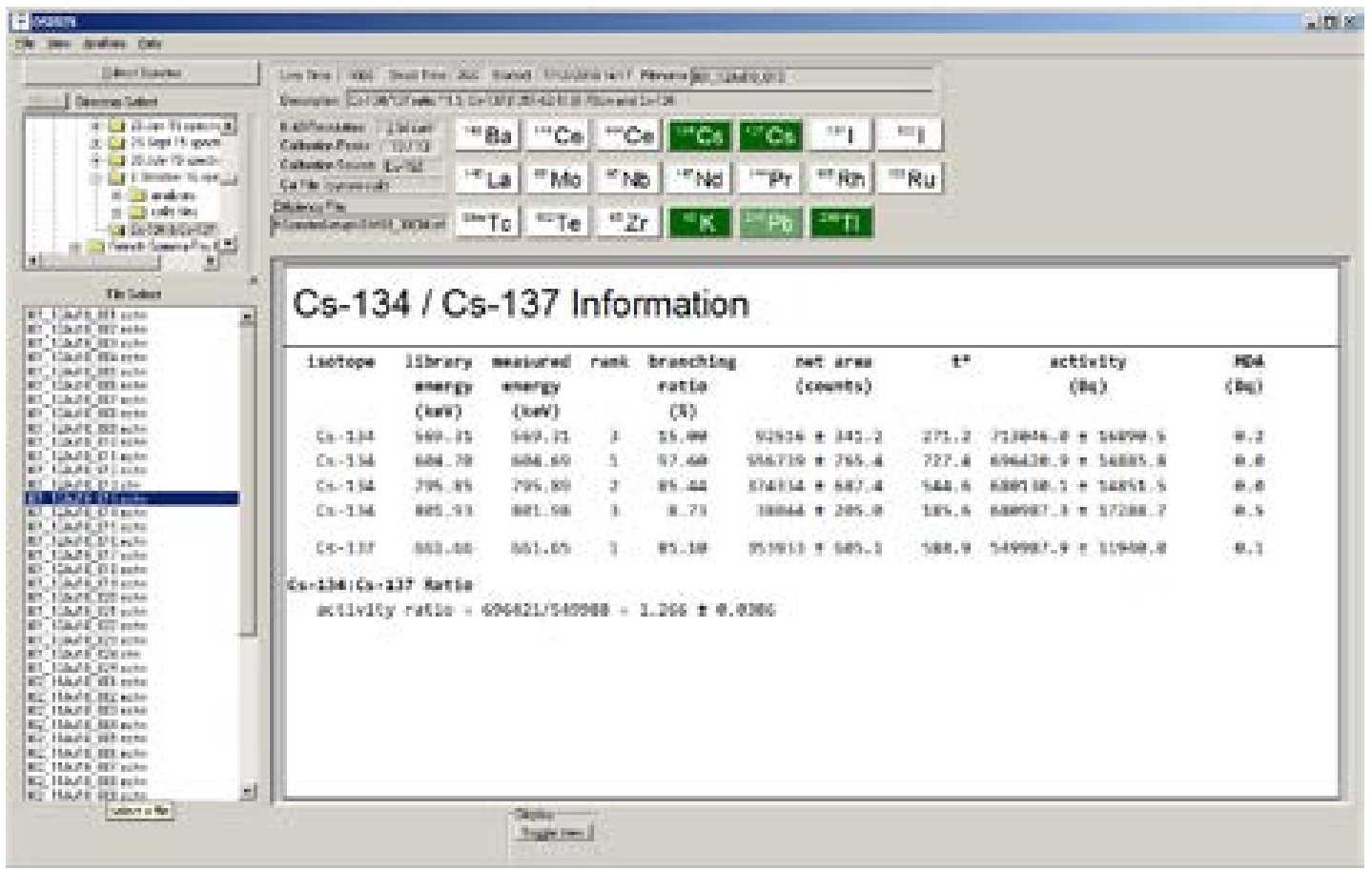

Figure 22. Cs-134/Cs-137 spectral information window. 
Since the Eckert \& Ziegler commercial fission product sources do not contain Cs-134, we have used individual Cs-134 and Cs-137 sources to verify that the activities of those isotopes is quantified correctly. An example Cs-134 and Cs-137 spectrum is shown in Figure 21, and the corresponding Cs-134/Cs-137 spectral information box, which includes the Cs-134/ Cs-137 activity ratio, is displayed in Figure 22.

\subsection{Fission-Product Identification Amid Nevada Test Site Legacy Radioactivity}

In March 2017, a field test of OsIRIS was conducted in two areas at the Nevada National Security Site, formerly the Nevada Test Site. Two OsIRIS instruments were operated in the in-situ (downward-looking) counting mode, and the radioactive background in one test area was a factor of 15 higher than in the other test area. A six-months-old fission-product source was placed 1 meter directly below the spectrometer during measurements, as shown in Figure 23. It was removed during background runs. While many of the short-lived isotopes in the source had decayed away, OsIRIS detected two CTBT-relevant fission products: 64-day Zr-95 and its 35-day daughter, Nb-95 at both test areas.

\subsubsection{Unscheduled Drop Test}

On the last day of testing in Nevada, a storm developed suddenly, and the related gale-force winds tossed the plastic shipping container where the notebook computer was being sheltered. Alas, the computer-spectrometer USB cable yanked over the spectrometer on its tripod, causing it to fall 1 meter ( 40 inches) to the ground. The spectrometer was sent to the ORTEC

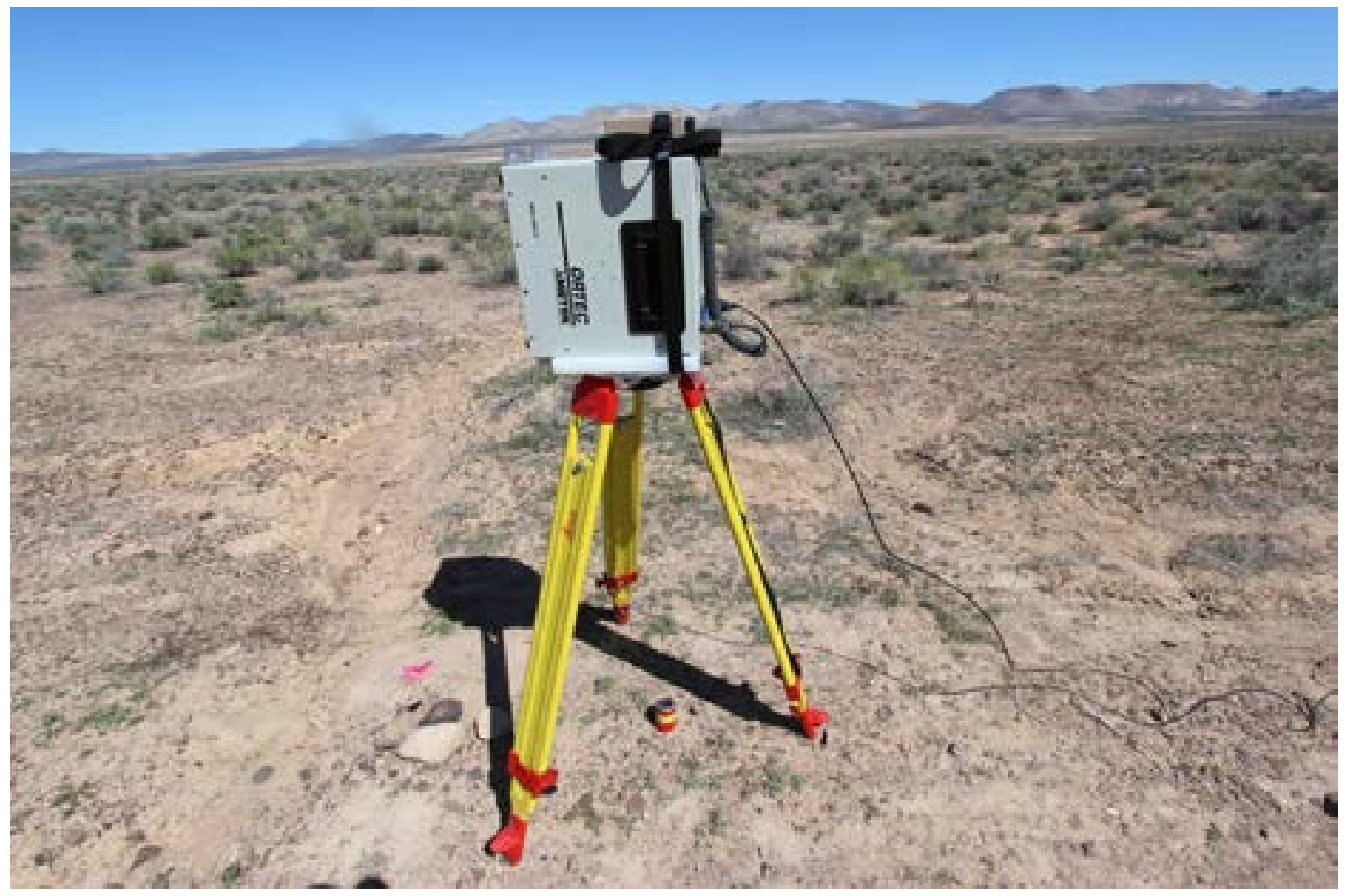

Figure 23. OSIRIS in-situ measurement in progress at Yucca Flat on the Nevada National Security Site, formerly the Nevada Test Site. 
factory for evaluation, and it was found to meet its original specifications. In short, it survived a 1-meter drop without damage, in keeping with the applicable standard for portable radiation detection instrument ruggedness. [29].

\subsection{Fission-Product identification vs. Time}

OSIRIS is designed to measure fission-product isotopes during an on-site inspection under the CTBT. To evaluate OsIRIS measurement accuracy, we recorded gamma-ray spectra from a fissionproduct radioactive source as it decayed. Our evaluation criterion is simple: do the OSIRIS spectroscopic data points match the known decay curves of fission-product isotopes?
We used a commercial 3-microcurie (0.12-megabecquerel) mixed-fission-product source containing all of the CTBT-relevant isotopes, save Cs-134 and Rh-106. [30] When new, this source produced the gamma-ray spectrum in Figure 2. OsIRIS counted the source almost every day, in order to follow fission-product decay for nearly one year at INL. Decay curves were calculated from fission-product half-lives, not from a least-squares fit to the experimental data. For $\mathrm{Nb}-95$, the daughter isotope of $\mathrm{Zr}-95$, the calculated curve includes parent-daughter effects. The decay curves for six representative CTBT-relevant isotopes (solid black lines) are compared to the measured spectral data (small colored circles) in Figure 24, and the agreement between the theoretical decay curves and the experimental data points is excellent.

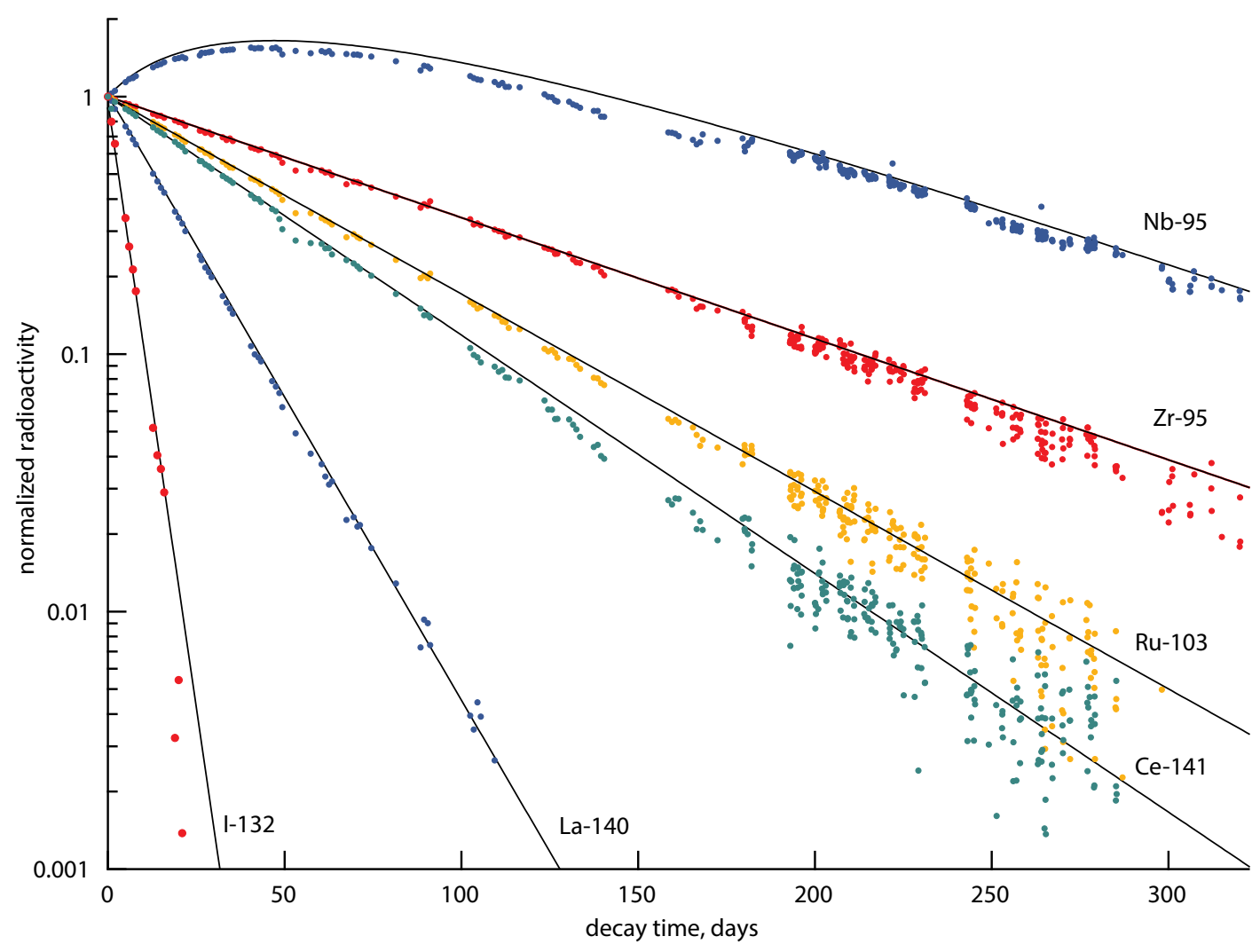

Figure 24. OSIRIS measurements of activity vs time for six CTBT-relevant fission-product isotopes. The solid black decay curves are calculated from fission-product half-lives, and the colored circles are experimental data points. 


\section{Conclusions}

The OsIRIS hardware and software has been specifically designed for the acquisition and analysis of high-resolution gamma-ray spectra during on-site inspections under the Comprehensive Nuclear-Test-Ban Treaty (CTBT).

Starting in 2014, extensive tests of OsIRIS have been conducted, to validate its design and verify its performance with fission-product measurements and data analysis.

\subsection{Design Summary}

The OSIRIS system hardware includes an ORTEC IDM-200-V high-purity germanium spectrometer, controlled by a ruggedized notebook computer running custom data acquisition and data analysis software. Similar instruments have been used by the U.S. military for over ten years.

The OsIRIS software design rests on code used for over twenty years in U.S. military field operations. The key software feature of the OsIRIS system is a data filter that limits its display to only radionuclide information relevant to CTBT on-site inspections.

\subsection{Testing Summary}

The OsIRIS gamma-ray spectrometer, then an ORTEC Transpec-100, was tested successfully at the 2014 Integrated Field Exercise (IFE14) in Jordan. Subsequently, the Transpec-100 was replaced by an ORTEC IDM-200-V spectrometer, for data security reasons.

A spectrum-blind instrument like OsIRIS must remain stable between energy calibrations, and hence we have tested the OsIRIS energycalibration stability versus time and temperature. In temperature tests over a $62^{\circ} \mathrm{C}\left(112^{\circ} \mathrm{F}\right)$ range, the OSIRIS calibration remained stable within 0.23 $\mathrm{keV}$. It is unlikely a spectrometer would encounter daily temperature changes this large during an on-site inspection. OsIRIS energy-calibration stability versus time was evaluated in month-long outdoor tests, in winter at INL and in summer at PNNL, and in these tests, the calibration remained stable within $0.11 \mathrm{keV}$.

Recently, OsIRIS was field-tested at the Nevada National Security Site. It identified two shortlived CTBT-relevant fission products amid legacy radioactive backgrounds, plus it survived an unplanned 1-meter drop test.

To characterize OSIRIS identification of CTBTrelevant radioisotopes, we measured gamma-ray spectra from a calibrated uranium fission-product source for almost one year. As the decay curves in Figure 13 attest, OsIRIS has correctly measured CTBT-relevant fission-product isotopes as their activities decayed by three orders of magnitude.

\subsection{Commercialization and Technical Readiness Level}

OsIRIS has recently been licensed to the ORTEC Division of AMETEK, Inc. To this end, we have designed custom shipping boxes for the hardware; tested a set of user-training-class materials, written a 100-page User's Manual [31], and created a software distribution/installation disk.

Given its extensive system testing and recent commercialization, the instrument now qualifies as Technical Readiness Level 8 (TRL-8).

\section{Acknowledgments}

OsIRIS research and development at INL, LLNL, and PNNL is sponsored by the Office of Nuclear Detonation Detection, NA-222, National Nuclear Security Administration, U.S. Department of Energy. 


\section{References}

1. CTBT, 1996, Comprehensive Nuclear-Test-Ban Treaty, Comprehensive Nuclear-Test-Ban Treaty Organization, https://www.ctbto.org/the-treaty/.

2. CTBT, reference 1. The Protocol, part II sets out the procedures for on-site inspections.

3. C. Carrigan, et al., "2009 noble gas field operations test," CTBTO Spectrum 15, 22-25 (November, 2010)

4. From the CTBT Protocol II text of reference 1: "89. Pursuant to Article IV, paragraph 57 (b) and paragraph 88 (a) above, the inspected State Party shall have the right throughout the inspection area to take measures to protect sensitive installations and locations and to prevent disclosure of confidential information not related to the purpose of the inspection. Such measures may include, inter alia: (a) Shrouding of sensitive displays, stores, and equipment; (b) Restricting measurements of radionuclide activity and nuclear radiation to determining the presence or absence of those types and energies of radiation relevant to the purpose of the inspection; ..."

5. "Refined List of Radionuclides of Interest for OSI [On-Site Inspections]", Comprehensive Nuclear-TestBan Treaty Organization Preparatory Commission paper CTBT/WGB/TL-4/42 (January 2012).

6. See, for example, A.J. Caffrey et al., "PINS-3 CF Chemical Identification System User's Manual v1.2", Idaho National Laboratory report INL/LTD-13-285877 (January 2016).

7. Technology Readiness and Maturation Guide, Version 1.0.", Office of Defense Nuclear Nonproliferation Research and Development, National Nuclear Security Administration, U.S. Department of Energy (October 1, 2014).

8. "Transpec-DX-100 Portable Integrated HPGe Spectrometer User's Manual", ORTEC Part No. 931042 (2009) 1-2, 63-68.

9. David Cramer, "The search for an underground nuclear test", Physics Today 68 (February 2015) 18-19. doi: 10.1063/PT.3.2680

10. See "IDM-200-V Interchangeable HPGe Detector Module.pdf", free download from www.ortec-online. $\mathrm{com}$

11. R.G. Helmer, and C.M. McCullagh, "GAUSS VII, a computer program for the analysis of $\gamma$-ray spectra from Ge semiconductor spectrometers", Nuclear Instruments and Methods in Physics Research 206 (1983) 477.
12. K. Debertin and R.G. Helmer, Gamma- and X-Ray Spectrometry with Semiconductor Detectors, (Amsterdam: Elsevier, 1988).

13. R.B. Firestone, editor, Table of Isotopes, Eighth Edition (New York: John Wiley \& Sons, Inc., 1996).

14. A.J. Caffrey, et al., "On-Site Inspection Radiolsotopic Spectroscopy (OSIRIS) System Development", Idaho National Laboratory report INL-EXT-15-35557 (2015) 12-15. doi:ID.2172/1228080

15. J.T.Goorley, et al., Initial MCNP6 Release Overview MCNP 6 version 1.0, Los Alamos National Laboratory Report LA-UR-13-22934 (2013).

16. W.K.Hensley, A.D.McKinnon, H.S.Miley, M.E.Panisko, and R.M.Savard, "SYNTH: A spectrum synthesizer", Nuclear Science Symposium and Medical Imaging Conference 1993, IEEE Conference Record (1993) 672-675.

17. A.J. Caffrey, et al., "OsIRIS—Gamma-ray spectroscopy software for on-site inspections under the Comprehensive Nuclear-Test-Ban Treaty", Nuclear Instruments \& Methods in Physics Research A784 405-411, doi:10.1016/j.nima.2014.10.066

18. https://www.ortec-online.com/products/ application-software/maestro-mca

19. https://www.mathworks.com/products/curvefitting/ features.html\#splines-andinterpolation

20. EML Procedures Manual, Environmental Measurement Laboratory Report HASL-300, 28th Edition. (February 1997); http://www.wipp.energy.gov/namp/ emllegacy/procman.htm

21. Huy, N.Q. and Binh, D.Q., "A semi-empirical approach to analyze the activities of cylindrical radioactive samples using gamma energies from 185 to 1764 keV". Appl. Radiat. Isotopes $9482-88$, (2014). http:// dx.doi.org 10.1016/j.apradiso.2014.07.013. Huy, N.Q., et al., "Self-absorption correction in determining the $238 \mathrm{U}$ activity of soil samples via 63.3-keV gamma ray using MCNP5 code". Appl. Radiat. Isotopes 71, 1 11-20, (2013). http://dx.doi.org/10.1016/j. apradiso.2012.09.004.

22. Warren, G.A. and Zalavadia, M., "A semi-empirical In-field soil sample efficiency calibration approach," to be published in Applied Radiation and Isotopes.

23. J.P. Holdren, Chair, "Monitoring Nuclear Weapons and Nuclear Explosive Materials", (Washington, DC: National Academy of Sciences, 2005) 107. 
24. Joan Daemen and Vincent Rijmen, The Design of Rijndael: AES - The Advanced Encryption Standard (Springer, 2002).

25. Federal Information Processing Standards Publication 197, United States National Institute of Standards and Technology, November 2001.

26. Rivest, R.; Shamir, A.; Adleman, L. (February 1978). "A Method for Obtaining Digital Signatures and Public-Key Cryptosystems", Communications of the ACM 21 (2): 120-126. doi:10.1145/359340.359342.

27. Federal Information Processing Standards Publication 180-4: Secure Hash Standard (SHS) (PDF, 1.7 MB) Current version of the Secure Hash Standard (SHA1,SHA-224, SHA-256, SHA-384, and SHA-512), March 2012.

28. M. Chino, et al., "Utilization of ${ }^{134} \mathrm{CS} /{ }^{137} \mathrm{Cs}$ in the environment to identify the reactor units that caused atmospheric releases during the Fukushima Daiichi accident", Nature Scientific Reports 6 (2016) article number 31376. https://doi.org/10.1038/srep31376

29. "American National Standard Performance Criteria for Handheld Instruments for the Detection and Identification of Radionuclides", IEEE Standard N42.34 (2015).

30. Eckert \& Ziegler Analytics MAF-GF-D mixed fissionproduct gamma-ray source. http://www.ezag.com

31. A.J. Caffrey et al., "OsIRIs User's Manual v. 1.0", Idaho National Laboratory report INL/MIS-17-42038 (December 2017). 
